Department of the Interior

U.S. Geological Survey

\title{
Temporal changes in grain size and organic-mineral aggregates in surficial sediments near the Massachusetts Bay Outfall Site
}

By

\author{
Richard R. Rendigs and Michael H. Bothner \\ U.S. Geological Survey \\ Woods Hole, MA 02543 \\ rrendigs@usgs.gov \\ mbothner@usgs.gov
}

USGS Open-File Report 01-499

December 2001

This report is preliminary and has not been reviewed for conformity with U.S. Geological Survey editorial standards (or with the North American Stratigraphic Code). Any use of trade, product or firm names is for descriptive purposes only and does not imply endorsement by the U.S. Government. 


\begin{abstract}
To assess the environmental impact of the Massachusetts Bay outfall for Boston's treated sewage effluent, grain size and characteristics of aggregates in bottom sediments have been measured during a comprehensive monitoring program. Both a sandy and a muddy bottom location within $2.5 \mathrm{~km}$ of the outfall have been sampled three times per year since 1990. These samples have provided about 11 years of pre-discharge baseline data used to evaluate natural variability.
\end{abstract}

The sandy location (station \#2) showed a very consistent textural trend over the monitoring period. Mean textural percentages were slightly over $97 \%$ sand, $1.5 \%$ silt, and $0.9 \%$ clay. The withinstation variability of the sand was less than $2 \%$. No seasonal differences in grain size were observed. There was very little change in the grain size distribution at this site following unusually large storms in October 1991 and December 1992. However, the concentration of aggregates, measured separately from the texture, decreased from about $1.5 \%$ to $0.5 \%$ after the December 1992 storm perhaps because of its longer duration. The aggregates at this station were composed primarily of quartz, with small concentrations of fecal pellets, worm tubes, and amorphous organic material all bound in an elastic mucus-like matrix. The majority of the fecal pellets were larger than $0.25 \mathrm{~mm}$, consistent with the size produced from an assemblage of benthic polychaetes, isopods, and amphipods.

The muddy location ( station \#3) contained 50-90\% silt plus clay. No seasonal textural trends were evident, but clay concentrations increased 35\% following the severe storm in December, 1992. Increases in clay concentration were also detected during February and May of 2001.These dates mark the 4th and 7th months after the September 2000 start of the new outfall. The ongoing monitoring study will compare these most recent and any future textural changes with chemical analyses of the sediments. The comparison will help to determine if a clear linkage can be made between the operation of the outfall and any changes observed in the sediments.

The organic mineral aggregates at station \#3 peaked (54\%) in concentration during the early fall of 1993 . Except for this peak, values were typically between $5 \%$ and $15 \%$ during the 11 year monitoring period. There were no seasonal trends. Speculation suggests that the peak in aggregate concentration may have been caused by larger populations of benthic organisms, which developed following the influx of fine-grained organic-matter-rich sediment after the unusual storm of December 1992. High concentrations of aggregates are restricted to the upper $2 \mathrm{~cm}$ based on profiles in sediment cores up to 50 $\mathrm{cm}$ long and suggests that this form of sediment encapsulation is fragile in the sedimentary record. 


\section{Introduction}

The United States Geological Survey (USGS) has conducted a multidisciplinary research program in Massachusetts Bay since 1989. The long-term goal of this project is to understand the fate and transport of contaminants that are adsorbed by suspended and bottom sediments. Studies have been conducted with a particular emphasis to monitor oceanographic, chemical, and geological conditions during the $\$ 4$ billion Boston Harbor cleanup effort. A major step in the harbor cleanup was completed on September 6, 2000 when the discharge of 380 million gallons per day of treated sewage effluent was switched from the harbor mouth to the new Massachusetts Bay Outfall located approximately nine miles offshore. Components of the USGS study have included geologic mapping, circulation and sediment transport observations, evaluation of heavymetal contamination, and modeling of ocean circulation and tidal exchange. A summary of the entire program is presented at the following web site: http://woodshole.er.usgs.gov/project-pages/bostonharbor/index.html

This report summarizes the time-series analyses of grain size distribution and the abundance of organic-mineral aggregates in surface sediments at two monitoring stations near the Massachusetts Bay Outfall. Sediments, especially the finer fractions, can adsorb contaminants from sea water and exert a strong influence on the transport and ultimate distribution of contaminants. Therefore it is important to know the extent to which sediment characteristics in Massachusetts Bay can change in response both to natural events, such as storms, and to the start of the new sewage outfall.

\section{Geologic Environment}

Massachusetts Bay encompasses an area enclosed by Cape Ann to the north, a limit defined to the east by Stellwagen Bank and Race Point on Cape Cod, to the south by Cape Cod Bay, and by the Massachusetts coast to the west (Figure 1).

Presently, the irregular sea-floor surface of Massachusetts Bay reflects complex events of multiple glaciations, isostatic rebound, subsequent marine incursion and modern sea-floor processes. There are two significant bathymetric features located within this inner shelf area: Stellwagen Bank located near its eastern limit and Stellwagen Basin between the bank and the 
coast. Preglacial fluvial erosion and glacial scour of the bedrock and coastal plain deposits produced large-scale bathymetric lows such as Stellwagen Basin and left large morphologic highs such as Stellwagen Bank (Oldale, 1993).

The inner shelf of Massachusetts Bay has been glaciated at least twice. Deposits of a preWisconsinan drift (Illinoian?), known as the lower or drumlin till, consists primarily of cobbles and boulders. A younger drift was deposited in the late-Wisconsinan time during the retreat of the marine-based Laurentide ice sheet. It consisted of a mixture of coarse ice-contact and outwash deposits of submarine origin and fine-grained glacial marine deposits (Oldale and Bick, 1987). After the ice retreated, glacial unloading of the depressed crust caused the shoreline to regress across the present inner shelf area. This regression produced a sea-level low stand at about 12,000 years BP of approximately $-43 \mathrm{~m}$ compared to that of present day sea-level (Oldale and others, 1993). This lowstand was followed by the Holocene marine incursion of the sea (in response to a eustatic rise of sea level), which truncated and eroded the glacial deposits. The incursion formed a transgressive unconformity atop this surface that in many places extends to the present day shoreline. Modern beach and bar deposits have formed on this surface both offshore and along the coast and have been subjected to a wave and current regime similar to that at present (Knebel and others, 1991).

Sediment sampling, benthic biology, and sea-floor mapping studies have provided much of the current knowledge on the types and spatial variability of the surficial sedimentary environments distributed in Massachusetts Bay (Schlee and others, 1973; Meisburger, 1976; SAIC, 1987; Oldale and Bick, 1987; Shea and others, 1991; Bothner and others, 1992; Hilbig and others, 1997). A synthesis of various sidescan-sonar surveys of Boston Harbor and the inner shelf of Massachusetts Bay (from the coastline out to the $50 \mathrm{~m}$ isobath) identified three categories of sedimentary environments. Within the confines of the study area, environments of erosion and nondeposition occupied slightly more than $70 \%$ of this area whereas areas of sediment reworking and deposition occupy 26 percent and 3 percent, (Knebel and Circe, 1995).

Bathymetric highs are probably remnants of glacially derived drumlins or ice-contact deposits. They contain coarse-grained sediments ranging from boulders and cobbles to wellsorted sands. These areas are characterized by high reflectivity and appear as lighter tones in the sidescan-sonar records (Figure 2). The depressions along the sea floor are localized topographic lows that contain finer grained sediments such as fine sands, silts, and clays. These areas tend to absorb sound more readily and appear as darker shaded areas on the records representing the 
ocean bottom.

USGS sampling stations \#2 and \#3 (water depths 33 and $35 \mathrm{~m}$, respectively) are classified as depositional based on the sidescan-sonar survey (Figure 2 and Bothner and others 1992). Bottom sampling and textural analyses indicated that sediment at station \#2 is fine sand and at station \#3 is mud.

\section{Methods}

The ongoing fieldwork and navigational support from 1989 to present has been carried out utilizing United States Coast Guard vessels from group Boston. Stations \#2 and \#3 were revisited three times per year and up to four cores collected from each site. From 1989 to 1992 navigation was based on multiple sextant angles with an estimated accuracy of $\pm 50 \mathrm{~m}$. In 1993 , navigation by the Differential Global Positioning System (DGPS) was routinely available with accuracy of $\pm 5 \mathrm{~m}$. In April 1998, the Coast Guard Cutter WHITE HEATH was replaced by the Cutter MARCUS HANNA which has dynamic positioning capability controlled by DGPS. With this system, cores can be collected with a better than $3 \mathrm{~m}$ precision if desired. In practice, cores are taken at random positions within a radius of about $20 \mathrm{~m}$ from the target position in order to minimize the chance of repeat sampling at precisely the same location.

The sediments were collected with a hydraulically damped gravity corer (Bothner and others, 1997; 1998) as shown in Figure 3. Once the coring system is gently placed on the bottom using the ship's winch, the 840-pound core head weight slowly forces the core tube into the sediment. The slow penetration is controlled by a preset water-filled piston. This slows and eliminates the bow wave caused by other types of fast-penetrating samplers (grab samplers and piston corers), and the surficial sediment is minimally disturbed. A "live feed" video camera is also attached to the corer, in order to view the bottom type and to assess any disturbance during the coring process.

In the laboratory, a plastic piston is inserted in the bottom of the core barrel and the core is secured vertically in a frame. The sediment is extruded upward in a controlled manner by the use of a "long throw" hydraulic jack, which pushes against the bottom of the piston. As the sediment is extruded, the outer rim of material in contact with the barrel is trimmed and discarded. The thickness of the core slices varies from $0.5 \mathrm{~cm}$ near the surface to $2 \mathrm{~cm}$ for depths greater than $10 \mathrm{~cm}$. The grain size samples are stored in a laboratory refrigerator until analysis.

The samples collected for grain-size analysis were processed according to a modified 
procedure from Anderson and others (1981) and is outlined on a flow sheet in Appendix 1. Analysis objectives were to preserve the biological components of the sediment, to optically identify the kinds of materials present, and to carry out routine grain size analyses. Each sample was gently wet sieved through 2-mm (-1 phi) and 0.0625-mm (4-phi) nested sieves using filtered seawater. The wash containing the fine fraction (silts and clays) was stored in a mason jar for analysis of the size distribution using a Coulter Counter. The coarse fraction retained on the 2mm sieve was dried and analyzed for gravel distribution. The sediment caught on the 4-phi sieve was gently re-sieved through $0.25-\mathrm{mm}$ (2-phi) and 0.0625-mm (4-phi) sieve. The sediment retained on these sieves includes biogenically-aggregated fines and both inorganic and organic detritus. A visual description and estimation of the aggregates using point count methods was accomplished using a light microscope under reflected light.

The sediment and aggregates were transferred from the sieves to a beaker and sonified in a water bath for 30 minutes to disaggregate fecal pellets and other organic aggregates (Anderson, 1981). The contents of the beaker were then passed through a 4 phi sieve and the wash retained in an underlying beaker. The amount of material finer than 4 phi generated during the sonification step was determined by filtering a known volume of the wash suspension using a pre-weighted Nucleopore filter and determining net weight after distilled water rinsing and air drying. Calculating the total solids weight in the wash provide an estimate of the operationally defined weight of organic-mineral aggregates in the sample.

The fraction (mostly sand) retained on the 4-phi sieve is reintroduced through nested sieves (whole phi intervals), and the weight percentage of each size fraction was determined.

The fines (silts and clays) collected in the mason jar were resuspended and a representative aliquot of solution filtered onto a pre-weighed Nucleopore filter. This was normalized and resulted in the weight of the fine fraction. The remaining fine fraction in the mason jar was analyzed on a Coulter Counter according to standard USGS laboratory techniques (Poppe and others, 2000).

The grain-size distribution of the sieved coarse sediment and the fines were processed through USGS sediment-laboratory computer programs. The complete grain-size distribution was reported for each sample, as calculated using the method of moments grain-size statistical analysis, and output on hard copy and on disc (Poppe and others, 2000).

A sample of well-mixed standard sediment was run with each suite of samples analyzed for grain size in order to monitor laboratory accuracy and precision. The standard is a silty sand 
collected on the New England Continental Shelf south of Martha's Vineyard. Results of the analyses of 16 standard sediment samples throughout the study varied within a narrow range. The sand content averaged $6.5 \% \pm 0.5 \%$. The mud content (silt plus clay) averaged $93.5 \% \pm$ $0.5 \%$.

\section{Results and Discussion \\ Station \#2 \\ Grain-size Analysis Results}

Results of grain-size analysis of the monitoring period at station \#2 from February 1990 to May 2001 are shown on Table 1 and Figure 4. The overall sediment texture of the interval from 0 to $0.5 \mathrm{~cm}$ has exhibited great consistency over time, with mean percent sand values exceeding $95 \%$ for the majority of the monitoring period (Table 1). Error bars of duplicate and triplicate samples indicate a within-station variability of sand typically less than $8 \%$ (Table 1 and Figure 4). On the basis of the size analysis results over the monitoring period, this station is classified as a moderately well sorted fine sand. Percent mud (silt plus clay) typically ranged from $0.5 \%$ to $5 \%$ (Figure 5 ).

A sediment texture map of the outfall area based on sediment profile imaging camera surveys identified major modal grain size and inferred kinetic energy on the benthic environment (Shea and others, 1991). On the map by Shea and others (1991), the USGS station \#2 falls within the boundaries of an area designated as a coarse sand to gravel. The fact that the USGS analyses and Hilbig and others (1997) indicate fine sand at station \#2 probably reflects a different methodology and the patchiness of sediment in this region.

A map of the major modal grain size of the surface sediments based on grab sampling of a 2-square-mile area west of the diffuser site further demonstrates and refines the spatial variability of the sedimentary environment regimes in this area (Hilbig and others, 1997). From this map, the USGS station \#2 falls within the fine sand mode environment defined by that study which also encompasses the diffuser site.

An apparent increase of $100 \%$ to $200 \%$ mud (silt plus clay) was evident from samples recovered from cruises W7 and W8 (October 1991 and February 1992, respectively) and represents higher mud concentrations than at any other sampling times between 1990 and 2000. However, only one of the duplicates from W8 contained an elevated mud concentration. There 
were no apparent errors associated with the collection, processing, or laboratory analyses of these samples to account for the slightly higher mud concentrations measured in W7 and W8 samples.

Fluctuations in the relative amounts of surficial sands and muds over time have also been observed comparing baseline data from 1992. Yearly sampling studies ensued through 1997 using sediment profile imaging and sediment grain size analyses of grab samples from monitoring sites in Massachusetts Bay (Hilbig and others, 1997: Blake and others, 1998). Surficial grain size fluctuations have been ascribed to the variety of sediment sources, their response during high runoff or storm related events, and the seasonal variability and activity of benthic infauna.

\section{Organic-Mineral Aggregates}

Organic-mineral aggregates were separated from the sediment with wet sieving techniques. Identifiable from microscopic observations, they were primarily composed of mineral grains with variable amounts of the following components: shell fragments, slag, plant fragments, rock fragments, Foraminifera tests, diatoms, copepods, unidentifiable larvae, sponge spicules, worm tube fragments, and fecal pellets.

These particles were bound in an amorphous elastic mucilaginous exudate. This mucuslike exudate is produced by the action of microbes, diatoms, and other benthic organisms living within the upper few centimeters of the sediment (Rhoads and Boyer, 1982). The mucus binds the individual particles together and may increase the bottom stress required for resuspension. The mucus matrix appeared colorless under both transmitted and reflected light, and the aggregate grains varied in size from 100 to 2000 micrometers as measured along the longest axis.

The aggregate fraction of the sediments was found to be consistently less than $2 \%$ by weight of the total sample throughout the 11-year monitoring period (Figure 6). The low percentage of aggregates may be related to the low percentage of silt and clay and the low abundance of benthic infauna (Rhoads and Boyer, 1982; Wheatcroft and others, 1994). There appears to be no seasonal trend for the occurrence of aggregates in the sediments. There was no difference between aggregates measured before and after the October 2001 storm (cruise W8). However, the aggregates were much lower on cruise W11 after the major storm with a longer duration, in December 1992.

The primary component of the aggregates were mineral grains, which commonly 
composed upwards of $95 \%$ of the total aggregate fraction. The predominant mineral grains were quartz ( $20 \%$ to $95 \%$ ), which varied in coloration from a clear translucent to a brownish coloration (due to iron staining). The grains were angular to subrounded, and some of the quartz grains appeared to be encrusted with organic matter. Other mineral grains present were micas, heavy minerals, feldspars, and unidentified silt- and clay-sized particles. The remaining components of the aggregates (shell and rock fragments, slag, and biogenic skeletal components) occurred in amounts typically less than $1 \%$ of the total.

Fecal pellets were the second most numerous component of the aggregate fraction. They are encapsulated waste products produced either by organisms living and feeding at the sedimentwater interface or by burrowing organisms such as tubiculous worms or other sediment-dwelling organisms (such as bivalves) which excrete the pellets at the sediment surface. These pellets generally totaled less than a few percent of the total aggregate components. The pellets were ellipsoidal and were retained primarily on the 2-phi $(0.25-\mathrm{mm}$, medium sand) sieve. Measurements of the long axis of the pellets ranged from 300 to 700 micrometers.

Results of long-term biological monitoring of western Massachusetts Bay has shown that a mixed benthic infauna assemblage is present near USGS station \#2 that is composed of polychaetes ( such as cirratulids, syllids, and spionids), amphipods and isopods. The infaunal density is low, and the species types are quite variable from year to year (Kim, written communication, 1992: Hilbig and others, 1997; Blake and others, 1998). Worm tube mats of polychaetes were not observed at the sediment-water interface in cores collected at this site by USGS investigators during the length of the monitoring period.

The mucus-bound aggregates are somewhat delicate and are easily disaggregated by typical treatments during laboratory grain-size analysis such as the use of dispersants, sonification, and drying. In nature, the aggregates are easily destroyed by near-bottom turbulence during storms and thus, they are not readily transported nor found intact at depth in the sediment (Rhoads and Germano, 1986).

\section{Station \#3}

\section{Grain-size Analysis Results}

Results of grain-size analysis for the monitoring period from February 1990 (cruise W2) through May 2001 (cruise MH36) at USGS station \#3 are shown on Table 1 and Figure 7. The overall sediment texture of the surficial interval from 0 to $0.5 \mathrm{~cm}$ is finer grained than that of 
station \#2 and somewhat more variable in distribution. The overall concentration of sand for station \#3 varied from $10 \%$ to $52 \%$, silt from $40 \%$ to $70 \%$, and clay from $5 \%$ to $47 \%$. Withinstation variability ranged from approximately $2 \%-15 \%$ for sand, $1 \%-13 \%$ for silt, and from $1.5 \%$ to almost $10 \%$ for clay (table 2 ). No seasonal differences were detected.

Results from the monitoring period indicate that the sediment at station \#3 is classified as coarse to medium silt based on the method of moments using mean phi values. The sediment contained greater than $50 \%$ mud (silts plus clays) over the entire monitoring period (figure 8).

No apparent effects to the overall grain-size distribution were evident from samples collected on W8 (February 1992) after the passage of the intense Halloween Nor'easter storm which occurred in October 1991. This storm had peak waves of $9 \mathrm{~m}$ for a few hours and waves greater than $5 \mathrm{~m}$ for 0.9 day. In contrast, the biggest change in grain size was found in samples collected on cruise W11 (February 1993) when the clay concentration had increased from about $10 \%$ to $45 \%$ (Figure 7). The W11 cruise followed a storm in December 1992 which had peak waves of $7.3 \mathrm{~m}$ and waves greater than $5 \mathrm{~m}$ for 2.6 days. The correlation of major storms and collection rates in sediment traps indicates that surface waves generated during Nor'east storms are the major cause of sediment resuspension in western Massachusetts Bay (Butman and others, 1992). We speculate that the 1992 storm, considerably longer in duration than the more intense 1991 storm, was responsible for resuspending and winnowing fine-grained material from surrounding areas, which accumulated, at least temporarily, in depositional areas like station \#3. Higher concentrations of silver and Clostridium perfringens in the W11 sample suggest that the storm transport included material originally deposited from the sewage outfall in Boston Harbor. The absence of a dramatic change in the grain size or sediment chemistry following the October 1991 cruise may indicate that the duration of resuspension processes was insufficient to move a significant mass of sediment. This increase in clay concentration may reflect the variability of sediment response to storms of different strength.

For station \#3, the grain-size distribution after sampling cruise W11 (February 1993) appeared to return to a somewhat siltier mode much like that as observed during the W2-W9 sampling cruises (Figure 5). However, cores collected during sampling cruises MH 35 and MH 36 (February 2001 and May 2001) also indicate an apparent increase in the concentration of claysized particles of $30 \%$ and $40 \%$, respectively (Figure 8). Examination of bottom current data collected at a nearby USGS mooring site indicates that only current events of low strength and short duration (not much longer than tidal cycles) occurred during these periods. No intense 
storms, such as the Halloween Nor'easter of 1991 or the December 1992 storm, were observed over these time frames. Changes within a sedimentary environment over time may simply reflect the natural variability in bottom sediment response to near-bed flow conditions (Snelgrove and Butman, 1994). We will be assessing the impact of the suspended material discharged from the Massachusetts Bay Outfall at station \#3. The concentrations of silver and Clostridium perfringens are not elevated in bottom sediment samples collected 6 months after the start of the outfall on September 6, 2000, compared with background values unrelated to storms (Bothner and others, 2001).

The depth profile of sand, silt, and clay percentages in two cores (3-1 and 3-3) collected on cruise W15 (June 1994) are in the same range but show maximums and minimums at different depth (Figures 9-12). The variability between these cores from the same location may be due to factors such as non-uniform bioturbation by sediment dwelling organisms, variability in net deposition on a small spatial scale, or by local disturbance of the bottom possibly by commercial fishing activity.

An additional core of over $50 \mathrm{~cm}$ in length was collected during a summer cruise (W24) in 1997. Figure 13 shows the textural variability with depth from core $3-4$. Trace gravel concentrations of slag, quartz, and shell fragments occur in the upper third and near the bottom of the core. Sand concentrations are highly variable in the upper $4-5 \mathrm{~cm}$ and near the bottom of the core, whereas from 5 to $23 \mathrm{~cm}$ the concentration of sand is fairly uniform, varying less than $15 \%$. Concentrations of mud throughout the core appear widely variable as well, ranging from $55 \%$ at the near surface to over $95 \%$ slightly below the midpoint of the core (Figure 14).

\section{Organic-Mineral Aggregates}

Components of the aggregates from station \#3 appeared visually similar to those collected at station \#2 as observed under the light microscope. The aggregates were bound within a clear to translucent mucus-like coating and consisted of mineral grains, rock fragments, diatoms, worm tube fragments, unidentifiable biogenic components, silt and clay size particles, shell fragments, slag, heavy minerals, and fecal pellets.

With the exception of two sampling cruises (W12 and W13), the weight percentage of the aggregate fraction was quite uniform with an average value of $7.8 \% \pm 4.6 \%$ that typically ranged from about $5 \%$ to $15 \%$ throughout the monitoring period. Significantly higher values of $27 \%$ and

$53 \%$ occurred during the summer and fall of 1993 (Figure 15, sampling cruises W12 and W13). 
Of these aggregates $75 \%$ were fecal pellets.

Fecal pellets were by far the most abundant non-mineral particle observed within the aggregates ranging from $25 \%$ to $90 \%$ of the total particles. The fecal pellets from station \#3 were smaller than those from station \#2. They were typically retained on the 4-phi $(0.0625-\mathrm{mm}$, very fine sand) sieve instead of the 2-phi $(0.25-\mathrm{mm}$, medium sand) sieve as at station \#2. The fecal pellets were ellipsoidal with the long axis between 60 to 150 micrometers in length. Because fecal pellet/aggregate formation might be expected to vary seasonally, the percent aggregates for each season were averaged (excluding W12 and W13). Mean values of weight percentages for samples collected in September $(7.8 \pm 4.3 \%)$, February $(6.7 \pm 3.4 \%)$, and May $(9.1 \pm 6.0 \%)$ are not statistically different.

The observed increases in the percentage of fecal pellets during the summer and fall of 1993 (cruises W12 and W13) correlate with similar increases of infauna abundance at station \#3 as well as from other nearby sites in Massachusetts Bay (Hilbig and others, 1997; Blake and others, 1998). The benthic community in Massachusetts Bay and at station \#3 is dominated by various species spionid polychaete worms that feed on surface deposits (Wheatcroft and others, 1994; Gallagher and Keay, 1998). This assemblage might experience episodic changes in numbers, distribution, and diversity due to the life cycles of the organisms, to sediment transport events, and to changes in the flux of organic matter from both natural and anthropogenic sources.

The increase in fecal pellet occurrence produced from the benthic infauna at station \#3 during the spring and fall of 1993 might also be a result of a "pulse" of fine-grained particles rich in organic matter that was deposited by the December 1992 storm. This new material could have been winnowed from the coarse sediment that exists landward of station \#3, or it could have come from the harbor itself.

The elevated concentrations of silver and Clostridium perfringens suggest that the source of contamination is from sewage (Bothner and others, 2001). However, these results do not distinguish whether the source of these sewage related components originated from Boston Harbor or from sources outside it on the inner continental shelf areas.

Organic-mineral-aggregate concentrations at the near surface of the sediments is about $21 \%$ and $24 \%$ for cores 3-1 and 3-3, respectively, collected in June of 1994 on cruise W15 (Figures 16 and 17). Both these concentrations decrease rapidly with depth in the core to less than $5 \%$ near the bottom of the core. The decrease of aggregates and fecal pellets with increasing core depth is probably due to the inherently fragile nature of the pellets. Also, these aggregates may be 
incorporated as a food source by other organisms within the sediment.

A plot of the aggregates from core 3-4 collected on cruise W27 in the summer of 1997 shows a maximum of slightly over $4 \%$ of aggregates at the surface with a more gradual decrease than cores 3-1 and 3-3, to less than $2 \%$ near the bottom of the core (Figure 18).

\section{Conclusions}

\section{Station \#2}

1. The distribution of sands, silts and clays in the surficial sediment $(0-0.5 \mathrm{~cm})$ at station \#2 showed very little change over the 11-year monitoring period except for two cruises (W7 and W8 conducted in October 1991 and February 1992). Excluding from these two cruises, the mean textural percentages were $97.6 \%$ sand, $1.5 \%$ silt and $0.9 \%$ clay and all samples were classified as well to moderately sorted fine sands. There appeared to be no seasonal differences in grainsize distribution.

2. A somewhat finer grain size distribution was observed in samples collected on cruise W7 (October 1991). The duplicate samples from cruise W8 (February 1992) contained widely varying sand percentages $(98.5 \%$ and $83.1 \%)$. We speculate that the W7 results are within the natural variability for field samples. The single low sand concentration (and high within station variability) on cruise W8 may reflect the impact of a major storm that struck coastal Massachusetts on October 31, 1991; however, the storm response at this station is not clear. Samples collected in February 1993 (W11) after another intense storm of longer duration, which occurred December 11-16,1992, showed no measurable change of grain-size distribution.

3. The layer from $0-0.5 \mathrm{~cm}$ contains a complex of organic-mineral aggregates bound by an elastic mucus-like membrane. Observations by light microscope confirmed that quartz composed up to $95 \%$ of the aggregates with small and variable amounts of fecal pellets, carapaces, worm tube fragments, and amorphous organic material. The weight percent of aggregates varied between 1$2 \%$ during the monitoring period and showed no seasonal trends.

Fecal pellets retained on the 2-phi sieve $(0.25-\mathrm{mm})$ were the most abundant organic component of the aggregates, and they were a minor component of the aggregate total. These pellets were produced by a mixed assemblage infauna including polychaetes, amphipods, and 
isopods.

\section{Station \#3}

1. The surficial sediment was muddier and more variable with time at station \#3 than at station \#2. This station is primarily silty in texture. Sand varied from $10 \%$ to $52 \%$, silts from $40 \%$ to $70 \%$, and clays from $5 \%$ to $47 \%$ over the entire monitoring period. No seasonal trends were evident.

2. The samples collected from station \#3 on February 1992 (W8) after the Halloween storm of 1991, showed virtually no change in the overall grain-size distribution from previous sampling cruises. However, samples collected after the storm on December 1992 showed an increase in concentrations of clay from about $10 \%$ to $45 \%$.

The difference in the response of sediment texture of the sample at station \#3 to different major storms may be related to the duration of the December 1992 storm, which generated waves higher than $5 \mathrm{~m}$ for 1.7 days longer than the storm in October 1991. The increase in clay content measured in February 1992 was accompanied by increases in concentrations of silver and Clostridium perfringens, both indicators of sewage particles (Bothner and others, 2001). These observations suggest that new sediment was transported to station \#3 from areas closer to Boston Harbor by the December 1992 storm.

Down-core textural characteristics in two cores from the same cruise and station (W15, cores 3-1 and 3-3) were similar in magnitude but maxima and minima in mud percentages occurred at different depths. The mud differences may reflect local variability in bioturbation and/or accumulation processes. The texture in a $50 \mathrm{~cm}$ core collected on cruise W24 was also variable with depth, and the core included small amounts of gravel sized particles.

3. The weight percent of organic-mineral aggregates in the sediment interval from 0 to $0.5 \mathrm{~cm}$ averaged between $5 \%$ and $15 \%$ over the 11 -year monitoring period, excluding spring and late summer sampling intervals following the major storm of December 1992. Although quartz was the major mineral grain of the aggregates, fecal pellets tended to be the major component of the organic fraction. Fecal pellets were smaller and more abundant than those found at station \#2 and were typically retained on the 4-phi sieve $(0.0625-\mathrm{mm})$. In the summer and fall of 1993 (cruises 
W12 and W13), aggregates (mostly fecal pellets) increased to $27 \%$ and 54\%, respectively, of the total sediment weight. We speculate that the storm of December 1992 deposited a new supply of fine-grained, organic-matter-rich sediments that supported higher populations of benthic infauna over the following summer.

Aggregate analysis with depth in cores collected on cruise W15 showed that the highest concentrations were restricted to the top few centimeters and decreased dramatically with depth. A more gradual decrease with depth was observed from a core collected on cruise W24.

\section{Acknowledgements}

We thank the captains, officers, and crews of the U.S. Coast Guard Cutters WHITE HEATH (1989 - 1998) and MARCUS HANNAH (1998 - Present) for their outstanding assistance at sea during the ongoing Massachusetts Bay Monitoring Program. Thanks are also extended to all USGS personnel who provided technical and operational assistance in the collection and analysis of sediment samples during the monitoring program.

\section{References}

Anderson, F.E., Black, L., Mayer, L.M., and Watling, L.E., 1981, A temporal and spatial study of mudflat texture: Northeastern Geology, v. 3, nos. 3/4, p. 184-191.

Blake, J.A., Williams, I.P., Gallagher, E.D., Hecker, B., Rhoads, D., and Arnofsky, P.L., 1998, Massachusetts Bay outfall monitoring program, benthic biology and sedimentology baseline monitoring for 1997 and retrospective analysis of the 1992-1997 database: Massachusetts Water Resources Authority, Environmental Quality Department Technical Report 98-16, 153 p.

Bothner, M.H., Parmenter, C.M., Twichell, D.C., Polloni, C.F. and Knebel, H.J., 1992, A Geologic map of the sea floor in western Massachusetts Bay, constructed From Digital sidescan sonar images, photography, and sediment samples, U.S. Geological Survey Digital Data Series DDS-3. 
Bothner, M.H., Casso, M.A., Rendigs, R.R., and Lamothe, P.J., 2001, Metal concentrations in suspended and bottom sediments since treated sewage discharge began at the Massachusetts Bay outfall: 2001 Annual Technical Workshop Benthic Monitoring and Fish/Shellfish Science Review, Battelle Laboratories, Duxbury, MA, April 6, 2001, 22 p. in press.

Bothner, M.H., Gill, P.W., Boothman, W.S., Taylor, B.B., and Karl, H.A., 1997, Chemical and textural characteristics of sediments at an EPA reference site for dredged material on the continental slope SW of the Farallon Islands: U.S. Geological Survey Open-File Report no. 97-87, 46 p.

Bothner, M.H., Gill, P.W., Boothman, W.S., Taylor, B.B., and Karl, H.A., 1998, Chemical gradients in sediment cores from an EPA reference site off the Farallon Islands - Assessing chemical indicators of dredged material disposal in the deep sea: Marine Pollution Bulletin, v. 36, no. 6, p. 443-457.

Butman, B., Bothner, M.H., Hathaway, J.C., Jenter, H.L., Knebel, H.J., Manheim, F.T., and Signell, R.P., 1992, Contaminant transport and accumulation in Massachusetts Bay and Boston Harbor: a summary of U.S. Geological Survey studies: U.S. Geological Survey Open-File Report 92-202, 42 p.

Gallagher, E.D., and Keay, K.E., 1998, Organism sediment contaminant interactions in Boston Harbor, in Contaminated sediments in Boston Harbor: Massachusetts Institute of Technology Sea Grant Publication, 98-1, 170 p.

Hilbig, B., Blake, J.A., Butler, E., Hecker, B., Rhoads, D., Wallace, G.T., and Williams, I.P., 1997, Massachusetts Bay outfall monitoring program: 1995 benthic biology and sedimentology: Massachusetts Water Resources Authority, Environmental Quality Department, Technical Report 96-5, 165 p. 
Knebel, H.J., and Circe, R.C., 1995, Maps and diagrams showing acoustic and textural characteristics and distribution of bottom sedimentary environments, Boston Harbor and Massachusetts Bay: U.S. Geological Survey Miscellaneous Field Studies Map MF-2280, 2 sheets.

Knebel, H.J., Rendigs, R.R., and Bothner, M.H., 1991, Modern sedimentary environments in Boston Harbor, Massachusetts: Journal of Sedimentary Petrology, v. 62, p. 791-804.

Meisburger, E.P., 1976, Geomorphology and sediments of western Massachusetts Bay: U.S. Army Coastal Engineering Research Center Technical Paper 76-3, 78 p.

Oldale, R.N., 1993, Geologic origins of Stellwagen Bank: The Cape Naturalist, 1993/1994, p. 27-31.

Oldale, R.N., and Bick, J., 1987, Maps and seismic profiles showing geology of the inner shelf, Massachusetts Bay, Massachusetts: U.S. Geological Survey Miscellaneous Field Studies Map, MF-1923, 4 sheets.

Oldale, R.N., Colman, S.M., and Jones, G.A., 1993, Radiocarbon ages from two submerged strandline features in the western Gulf of Maine and a sea-level curve for the Northeastern Massachusetts coastal region: Quaternary Research, v. 40, p. 38-45.

Poppe, L.J., Elaison, A.H., Fredericks, J.J., Rendigs, R.R., Blackwood, D., and Polloni, C.F., 2000, Grain size analysis of marine sediments; methodology and data processing, in U.S. Geological Survey East Coast sediment analysis: procedures, database, and georeferenced displays: U.S. Geological Survey Open-File Report 00-358, CD-Rom.

Rhoads, D.C., and Boyer, L.F., 1982, The effects of marine benthos on physical properties of sediments, in McCall, P.L. and Tevez, M.S.J. eds., Animal-sediment relations: New York, Plenum Press, p. 3-52. 
Rhoads, D.C., and Germano, J.D., 1986, Interpreting long-term changes in benthic community structure: a new protocol: Hydrobiologia, v. 142, p. 291-308.

SAIC, 1987, REMOTS survey of Broad Sound Massachusetts Bay, Report no. SAIC$87 / 7511$ and 141, draft report submitted by Scientific Applications International Corporation to Stone and Webster Engineering Corporation.

Schlee, J., Folger, D.W., and O'Hara, C.J., 1973, Bottom sediments on the continental shelf off the northeastern United States-Cape Cod to Cape Ann, Massachusetts: U.S. Geological Survey Miiscellaneous Geologic Investigations, Map I-746, 2 sheets.

Shea, D., Lewis, D.D., Buxton, B., Rhoads, D.C., and Blake, J.A., 1991, The sedimentary environmentof Massachusetts Bay: Physical, biological, and chemical characteristics: prepared for Massachusetts Water Resources Authority, Charlestown Navy Yard, 100 First Avenue, Boston, Massachusetts, 81 p.

Snelgrove, V.R., and Butman, C.A., 1994, Animal sediment relationships revisited: cause versus effect: Oceanography and Marine Biology: An Annual Review, v. 32, p. $111-$ 177.

Wheatcroft, R.A., Olmez, I., and Pink, F.X., 1994, Particle bioturbation in Massachusetts Bay; Preliminary results using a deliberate tracer technique: Journal of Marine Research, v. 52 , p. $1129-1150$. 


\section{List of Figures}

1. Location of the Massachusetts Bay outfall site showing its proximity to the Stellwagen Bank National Marine Sanctuary to the east and Cape Cod to the south. MBDS is the Massachusetts Bay disposal site for dredged material.

2. A sidescan sonar map (looking northward) depicting the bathymetry and locations of the two USGS long-term monitoring sites (stations \#2 and \#3) and their proximity to the outfall diffuser pipe.

3. The Hydrodynamic Core used to collect relatively undisturbed sediment cores at USGS stations \#2 and \#3 in western Massachusetts Bay.

4. Results of grain-size analyses from cruises between December 1989 and May 2001 of the $0-0.5 \mathrm{~cm}$ surficial sediment interval from the fine sandy station \#2. The annotation of $\mathrm{W}$ on the $\mathrm{x}$ axis= USCGC Whiteheath; MH= USCGC Marcus Hannah.

5. A plot of the percent mud from station $\# 2$ for the monitoring period from cruises between December 1989 and May 2001.

6. Weight percent aggregates from station \#2 display a consistent trend and magnitude from cruises between December 1989 and May 2001.

7. Grain-size-analysis results from the muddy station \#3 show more variability of the textural components over time than station \#2. The annotation of W on the $x$ axis= USCGC Whiteheath; MH= USCGC Marcus Hannah.

8. Percent (\%) mud from station \#3 shows a high variability over time.

9. Sediment variability within core 3-1 collected on cruise w15 in western Massachusetts Bay.

10. Sediment variability within core 3-3 collected on cruise w15 in western Massachusetts Bay.

11. The variability of mud with depth in a core as determined from grain-size analysis from core 3-1 collected on cruise w15.

12. The variability of mud with depth in a core as determined from grain-size analysis from core 3-3 collected on cruise w15.

13. Grain-size distribution of core 3-4 collected on cruise w24 shows traces of gravel with 
increased depth within the core.

14. Highly variable mud concentrations throughout core 3-4 approach greater than $95 \%$ at depth.

15. A plot of the weight percent (\%) of naturally occurring aggregates in the sediments from station \#3 showing a fairly consistent trend (except for cruise 12 and 13) over the monitoring pro program.

16. Organic-mineral aggregate analysis of core 3-1 from cruise w15 shows a significant decrease in the concentration of aggregates from the near surface to slightly below $1.5 \mathrm{~cm}$.

17. Organic-mineral aggregate analysis of core 3-3 from cruise w15 shows a similar decrease in the concentrations of aggregates with sampling depth in the core as that of core 3-1.

18. This plot shows a slightly less varied aggregate concentration as sampled from core 34 collected at USGS station \#3 on cruise W24.

\section{List of Tables}

1. Results of grain size analysis for the surficial interval from 0 to $0.5 \mathrm{~cm}$ of cores collected from long term monitoring stations \#2 and \#3 near the sewage outfall site in Massachusetts Bay.

2. Grain size statistics the $0-0.5 \mathrm{~cm}$ surficial interval of cores collected from long term monitoring stations \#2 and \#3 near the sewage outfall site in Massachusetts Bay.

\section{Appendix}

1. Flow chart showing the laboratory procedure for organic-mineral aggregate and grain size analysis for the $0-0.5 \mathrm{~cm}$ surficial interval of cores collected at USGS stations \#2 and \#3 in Massachusetts Bay (modified from Anderson and others, 1981). 


\section{APPENDIX 1 \\ Flow chart detailing the Massachusetts Bay textural analysis procedure of the 0-0.5 cm surficial interval as sampled from Hydrodynamic Gravity Cores}

Using nested stainless steel sieves of mesh size -1 phi $(2.0 \mathrm{~mm})$ and 4 phi $(0.0625 \mathrm{~mm})$, gently wet sieve a split of wet sediment, using aliquots of 0.2 um filtered seawater with $80 \mathrm{ml}$ formalin diluted to 20 liters. The fine fraction is retained in a mason jar. Transfer the coarse fraction retained on the 4 phi sieve to a $100 \mathrm{ml}$ beaker (dry and weigh any gravels retained on the $2.0 \mathrm{~mm}$ sieve) and proceed with the analyses for each fraction as outlined below:

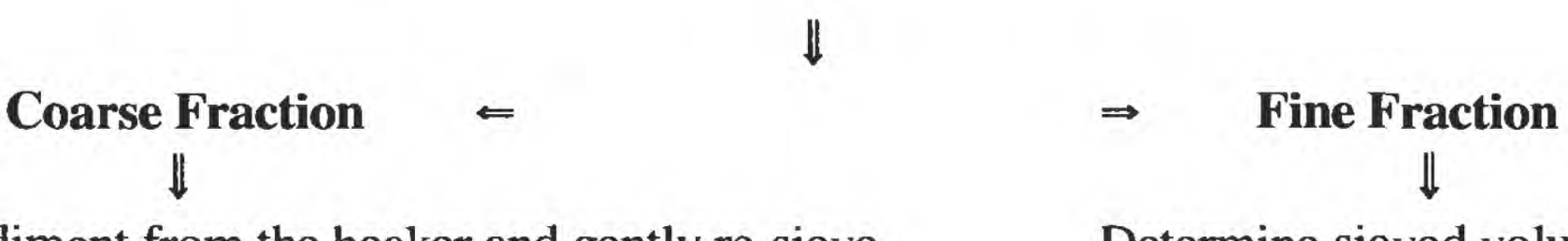

transfer the sediment from the beaker and gently re-sieve through a set of nested 2 phi and 4 phi sieves using filtered sea water and add the wash to the fine fraction in the mason jar

Determine sieved volume using a graduated cylinder, Record and return solution to the mason jar

$\Downarrow$

examine the sediment retained on each sieve using a light microscope; characterize particles as to detrital, aggregates, fecal pellets, etc. and, qualitatively, determine relative percentages of each.

transfer contents from each sieve to a $100 \mathrm{ml}$ glass beaker with filtered seawater and sonify in a sonic bath for 30 minutes

$\Downarrow$

re-sieve contents through a 4 phi sieve using a $200 \mathrm{ml}$ tallboy beaker as a catch pan

$\downarrow$
Return sediment retained on 4 phi
sieve for standard size analysis
using whole phi nested sieves
(include -1 phi fraction as well)

resuspend the filtrate with a motorized stirrer and transfer an aliquot of sieved solution with a pipette and filter through a standard millipore filtration rig using a pre-weighed

Homogenize solution with a stir bar and extract 10-20 ml with a pipette; transfer to a millipore rig using a preweighed $47 \mathrm{~mm}$ diameter/ 0.4 um nucleopore filter; filter solution and rinse five times with fdw-record both volumes $\Downarrow$ dry filter overnight under a laminar flow hood; determine weight of sediment (g)- this is weight of fines in the sample

analyze the solution in the mason jar by standard coulter counter methods- this will 
$47 \mathrm{~mm}$ diameter/0.4 um nucleopore filter; rinse filter and sediment 5 times with filter distilled water and record volume of aliquot filtered and final volume collected in the flask with a graduated cylinder;

$\Downarrow$

transfer filter to a petrie dish and dry overnight under a laminar flow hood; record weight of filter and determine weight of sediment normalized to grams. This is an operationally defined measure of the weight of aggregates within the sample. determine the distribution of silt and clay sized particles within the sample 


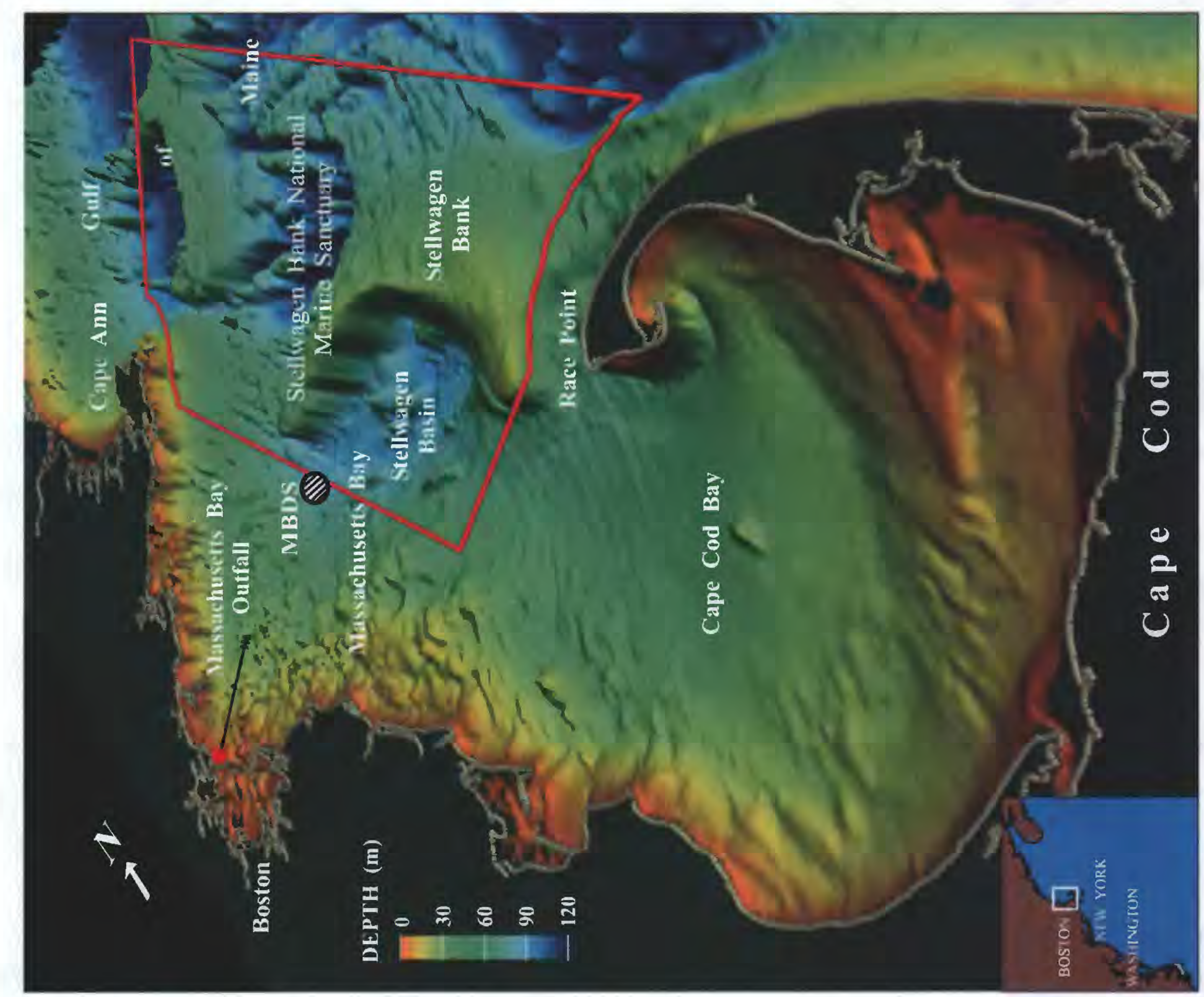

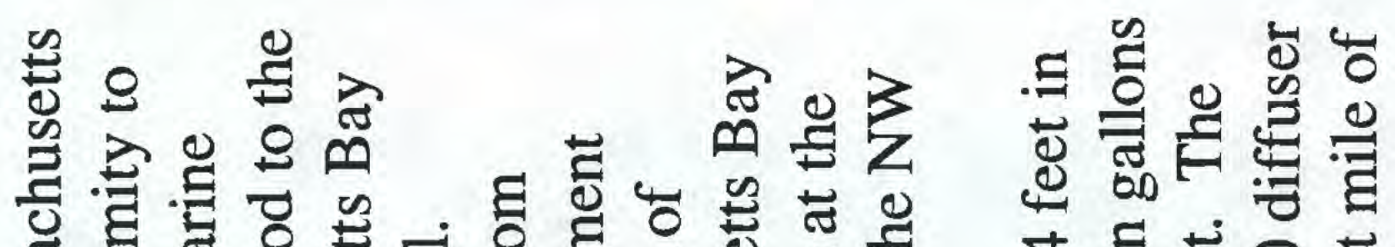

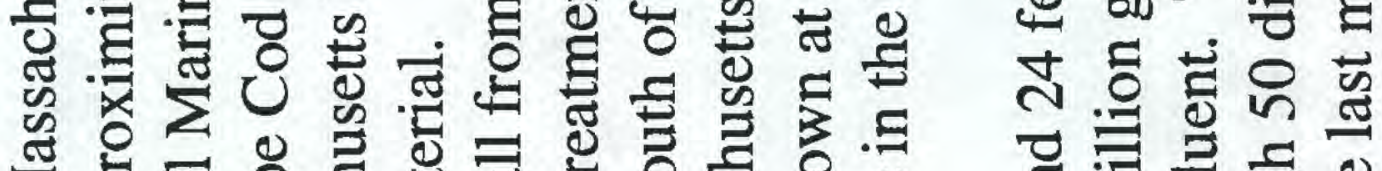

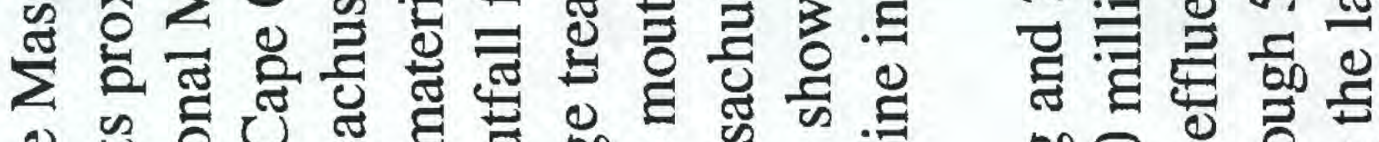
o.

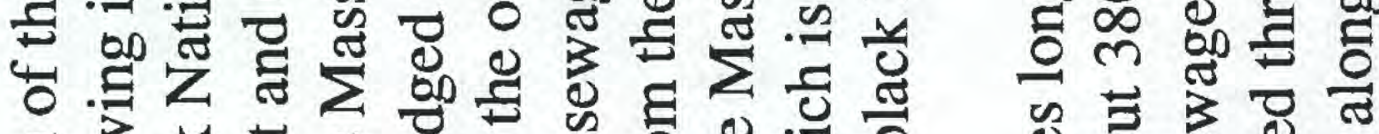
드을

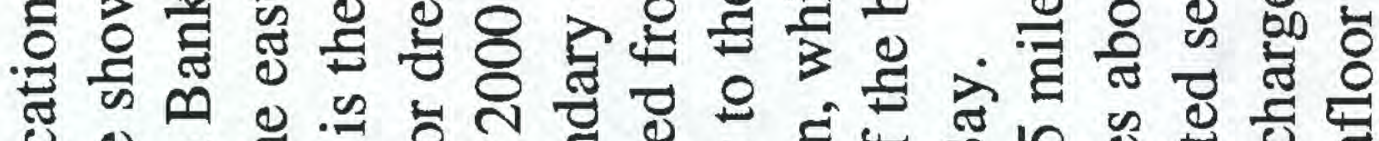
s.든

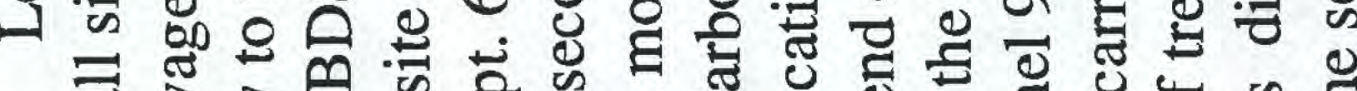

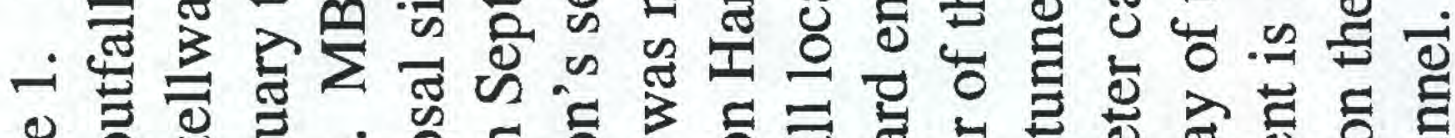

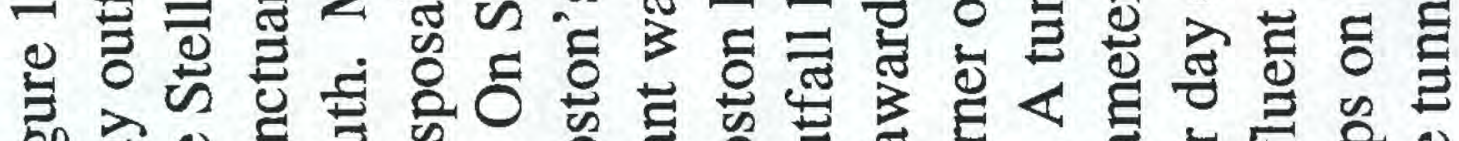

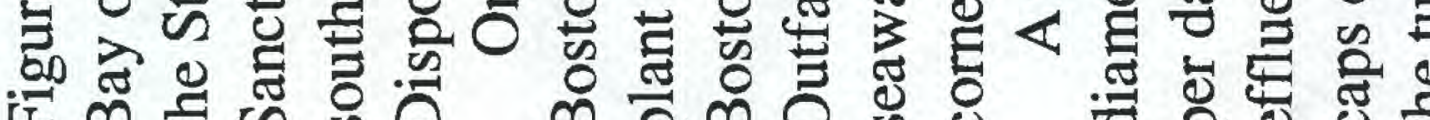

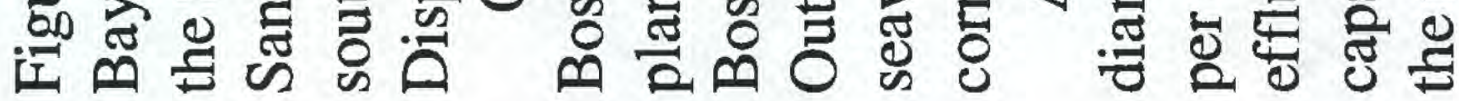








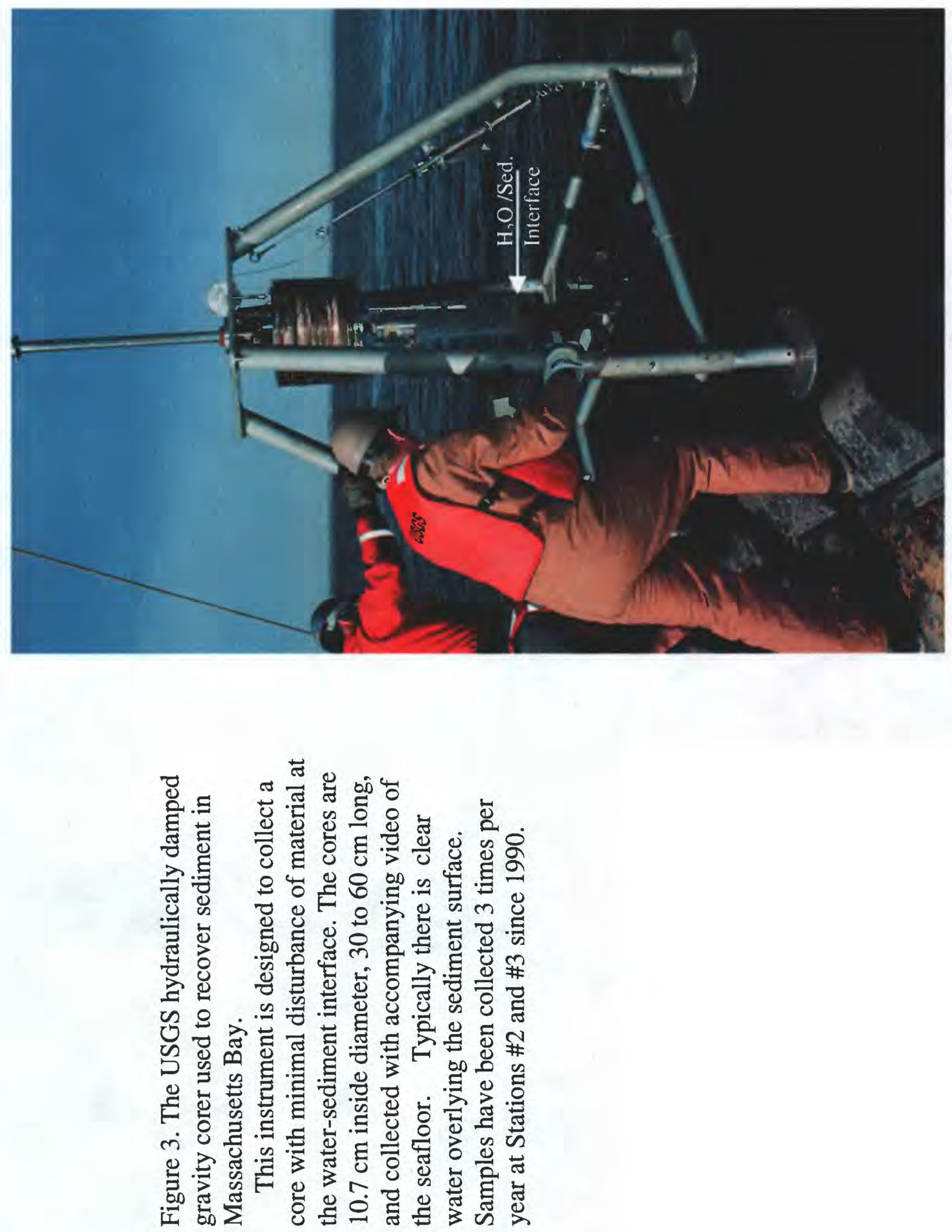


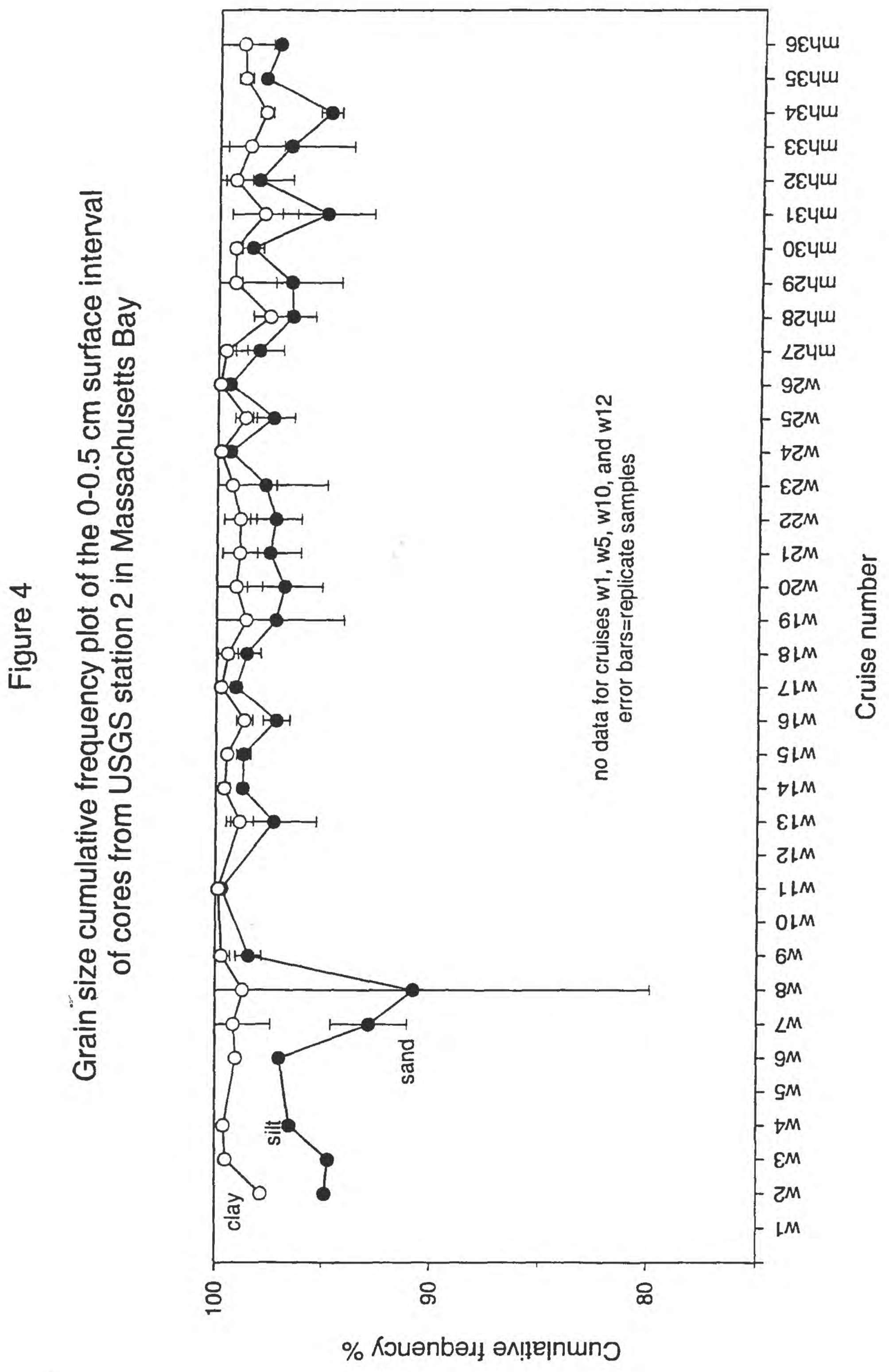




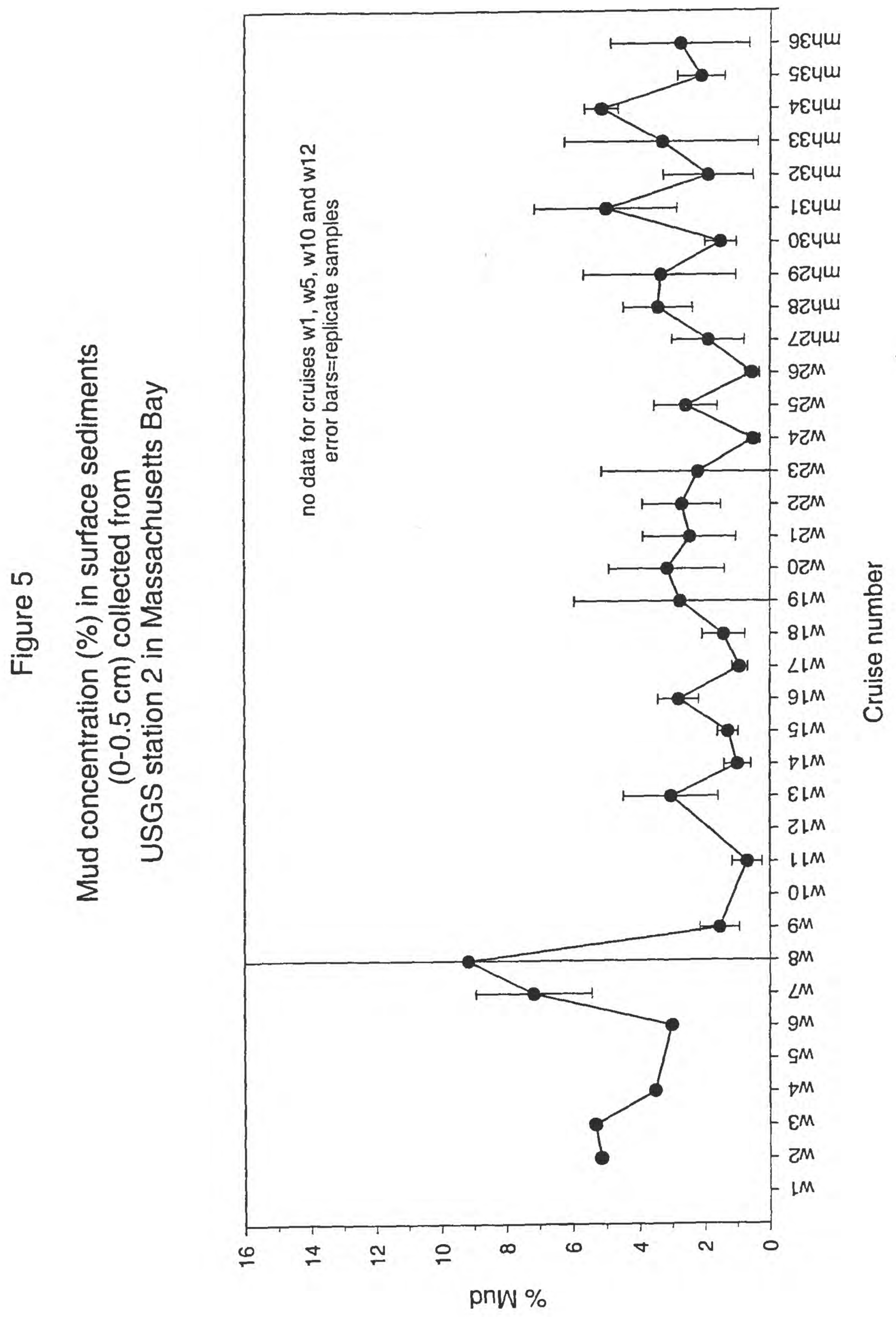




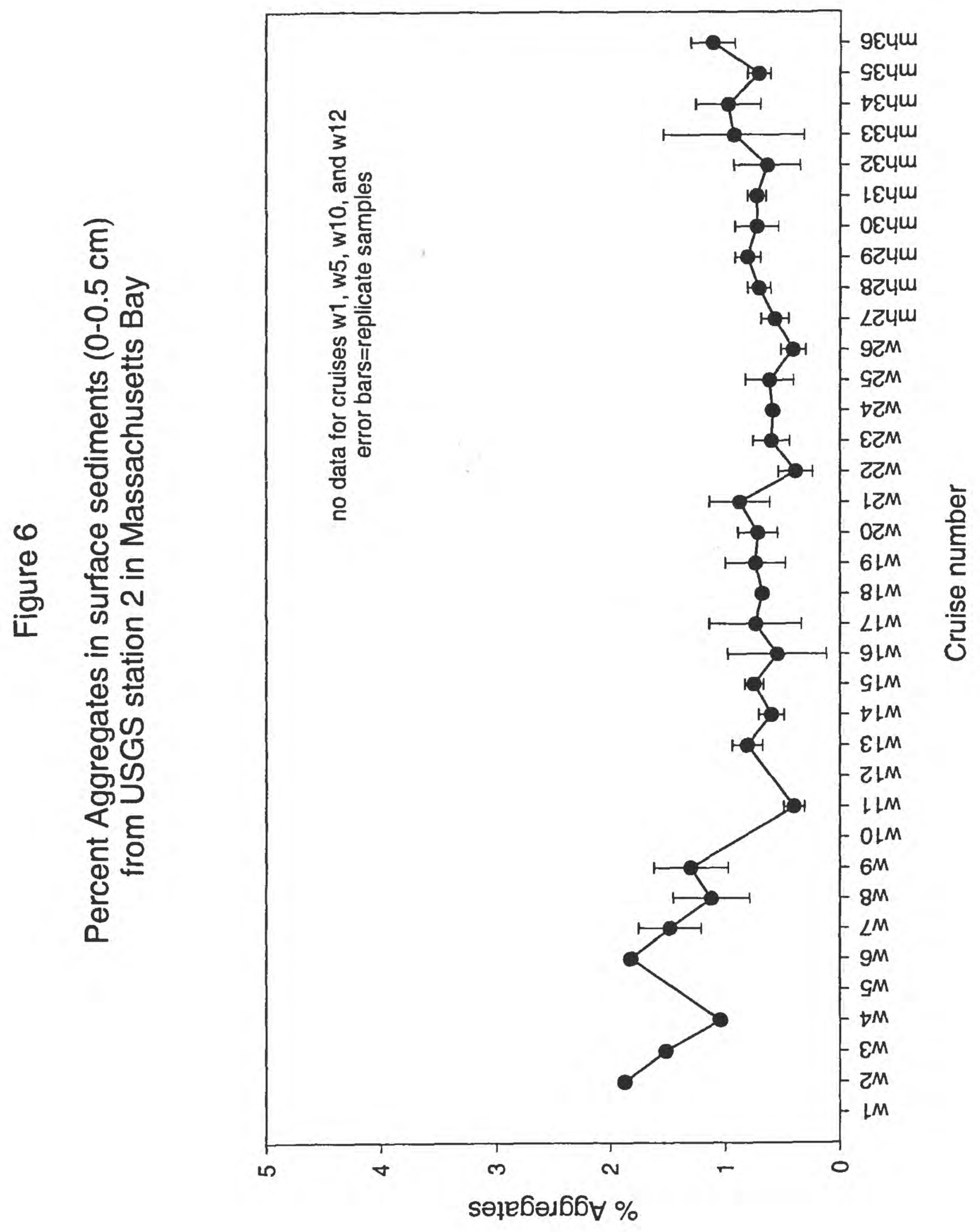




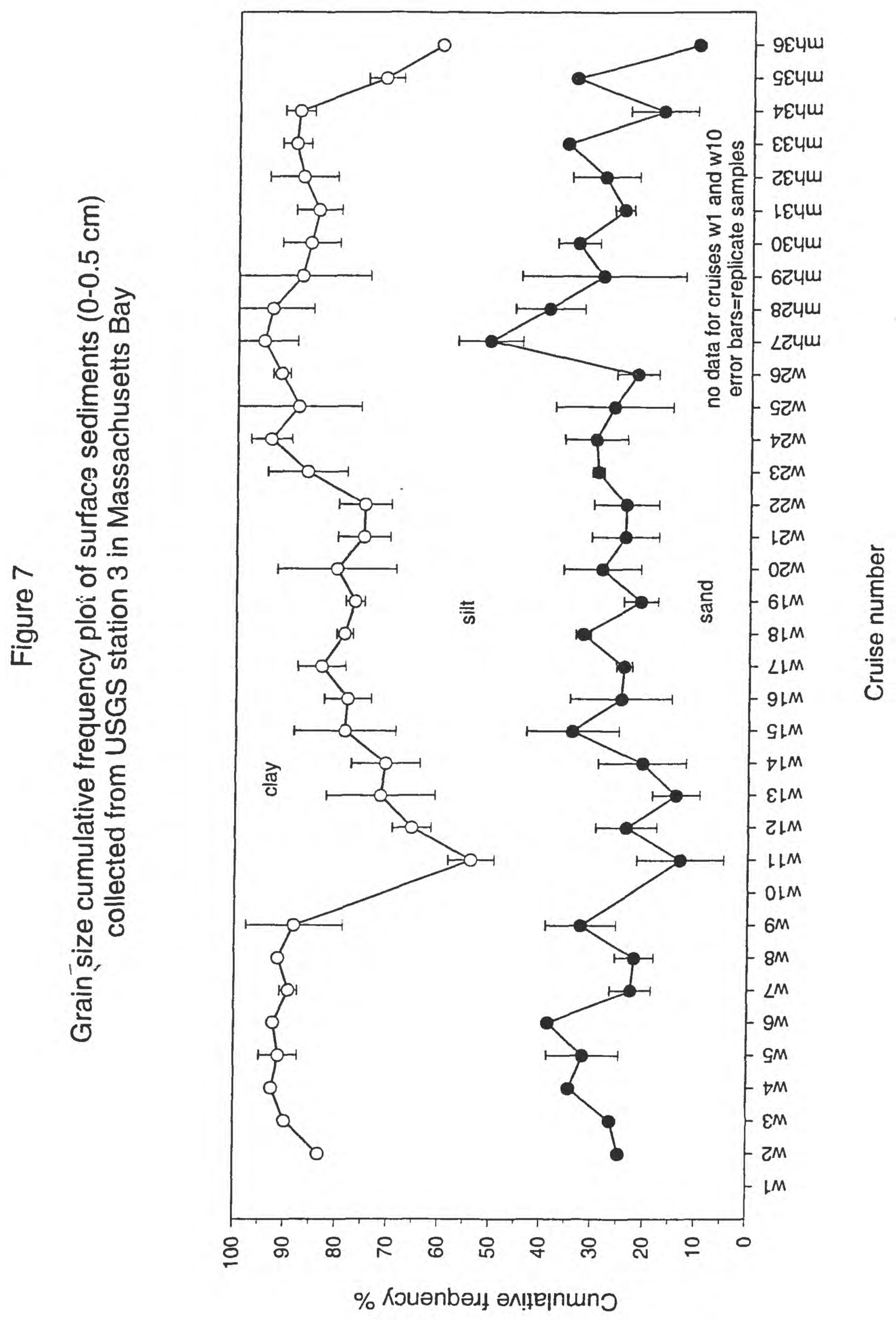




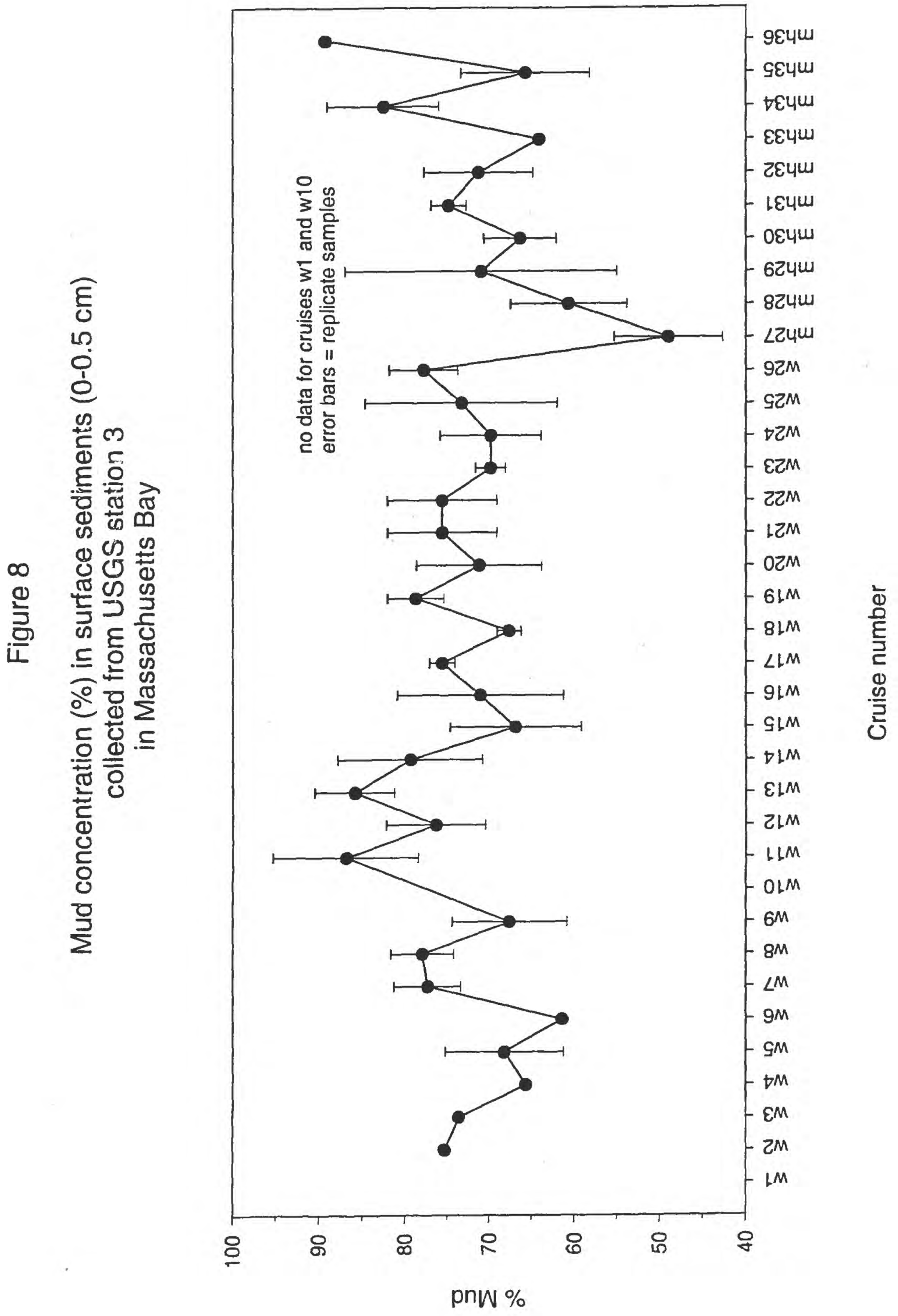


Figure 9

Grain size cumulative frequency with depth in core 3-1 collected on cruise w15 at USGS station 3 in Massachusetts Bay

Cumulative Frequency \%

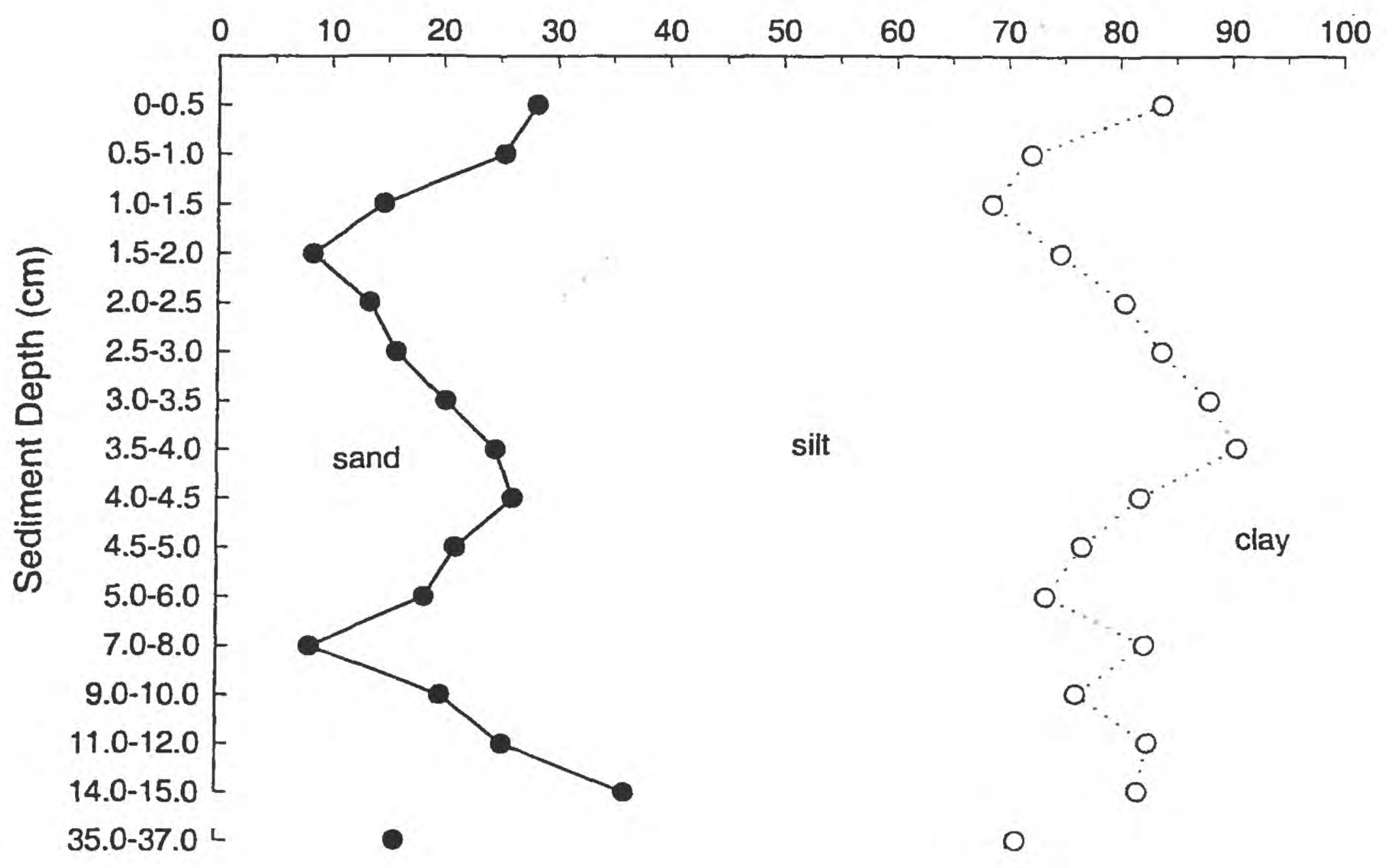


Figure 10

Grain size cumulative frequency with depth in core 3-3 collected on cruise w15 at USGS station 3 in Massachusetts Bay

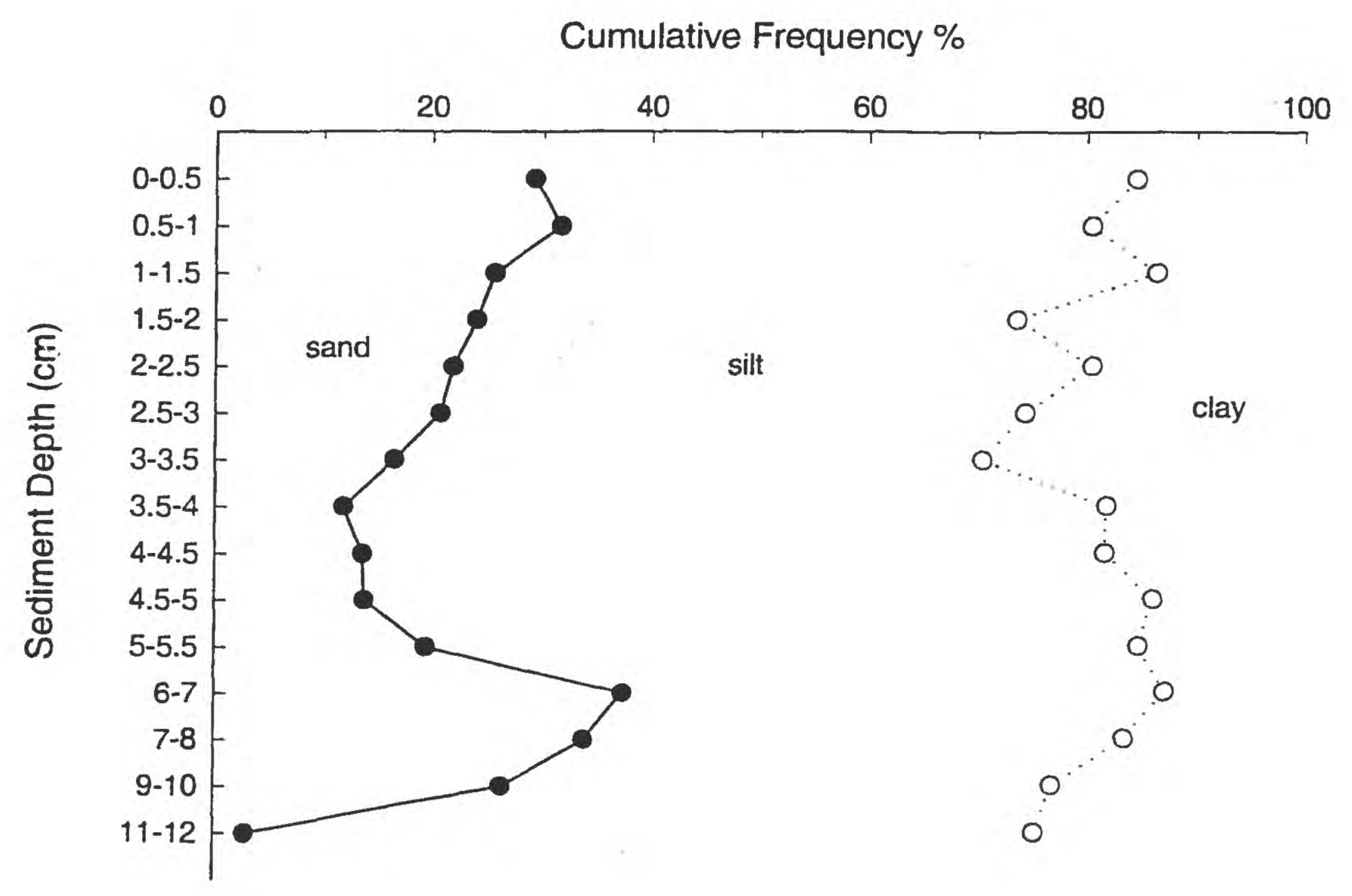


Figure 11

Mud concentration (\%) with sediment depth in core 3-1 collected on cruise w15 at USGS station 3 in Massachusetts Bay

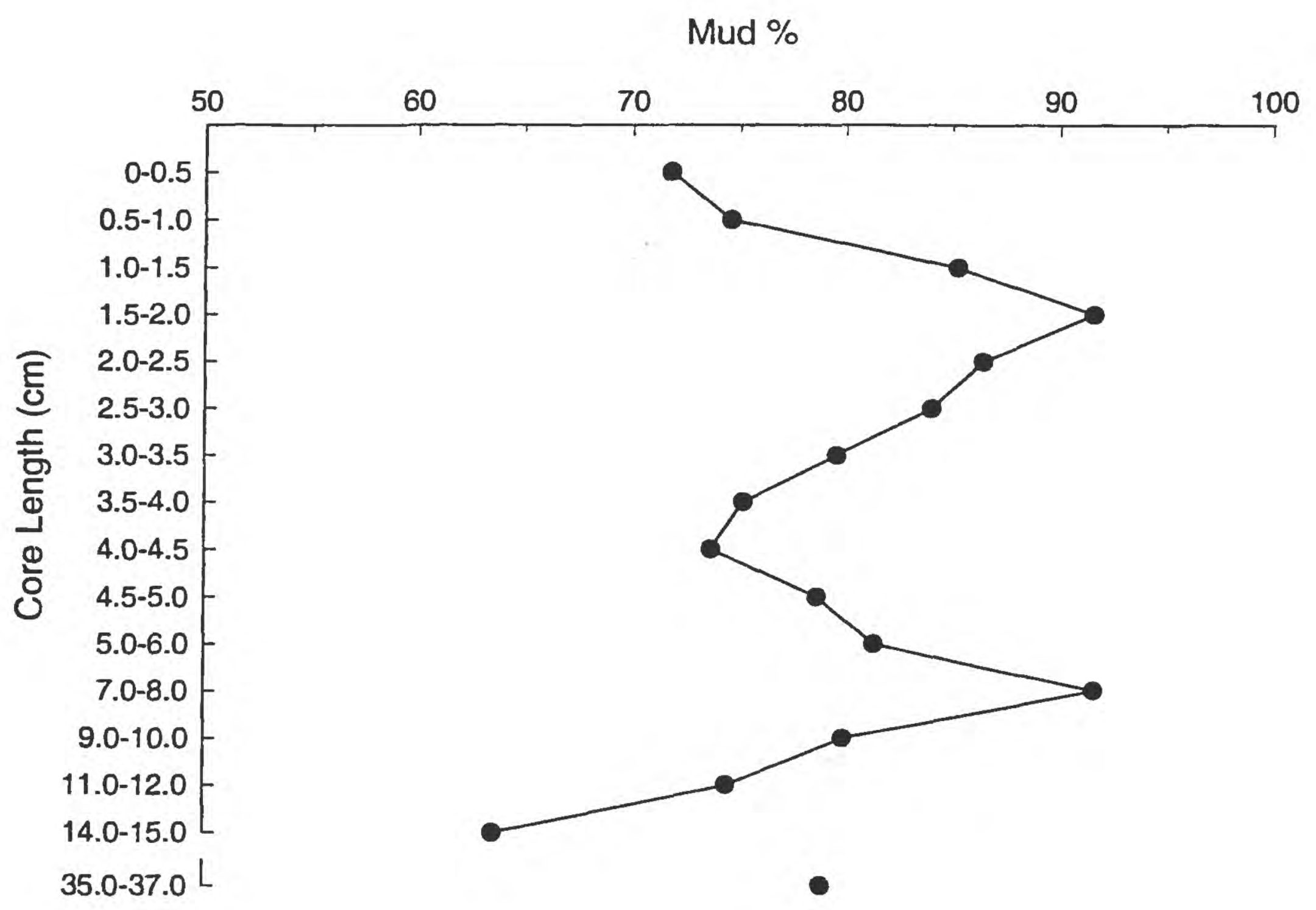


Figure 12

Mud concentration (\%) in core 3-3 collected on cruise w15 at USGS station 3 in Massachusetts Bay

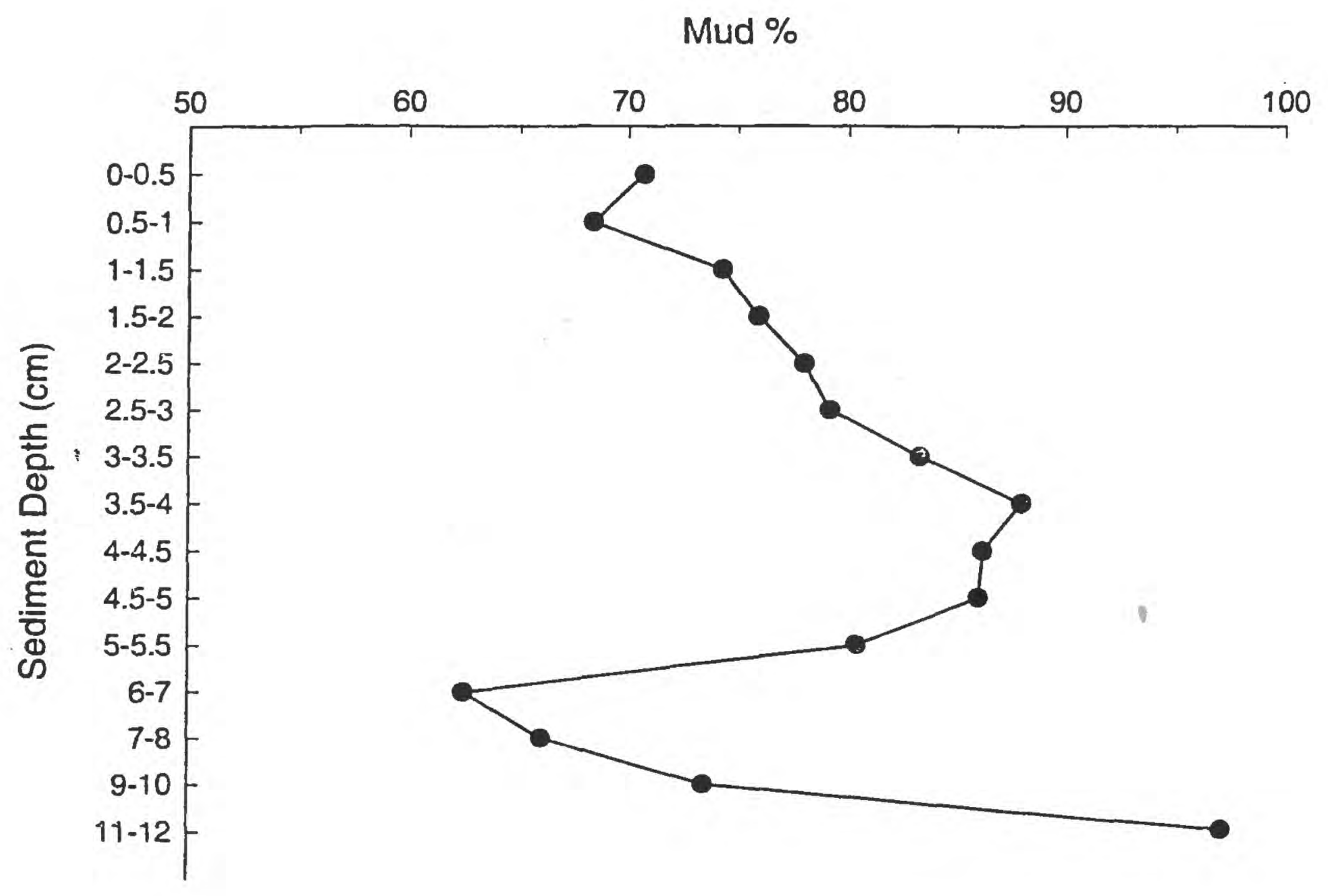


Figure 13

Grain size cumulative frequency in core 3-4 collected on cruise w24 at USGS station 3 in Massachusetts Bay

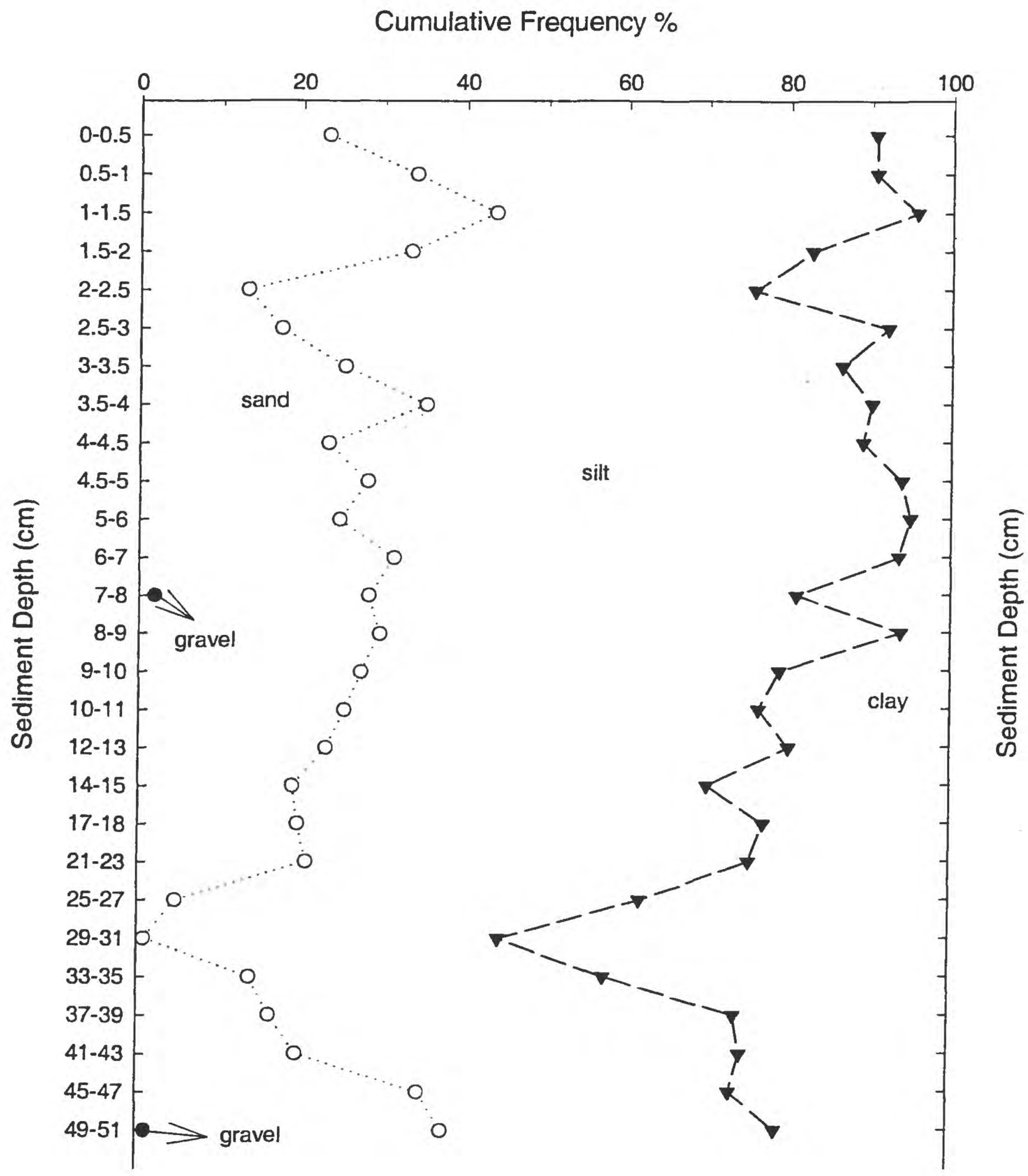


Figure 14

Mud concentration (\%) with sediment depth in core 3-4 collected on cruise w24 at USGS station 3 in Massachusetts Bay

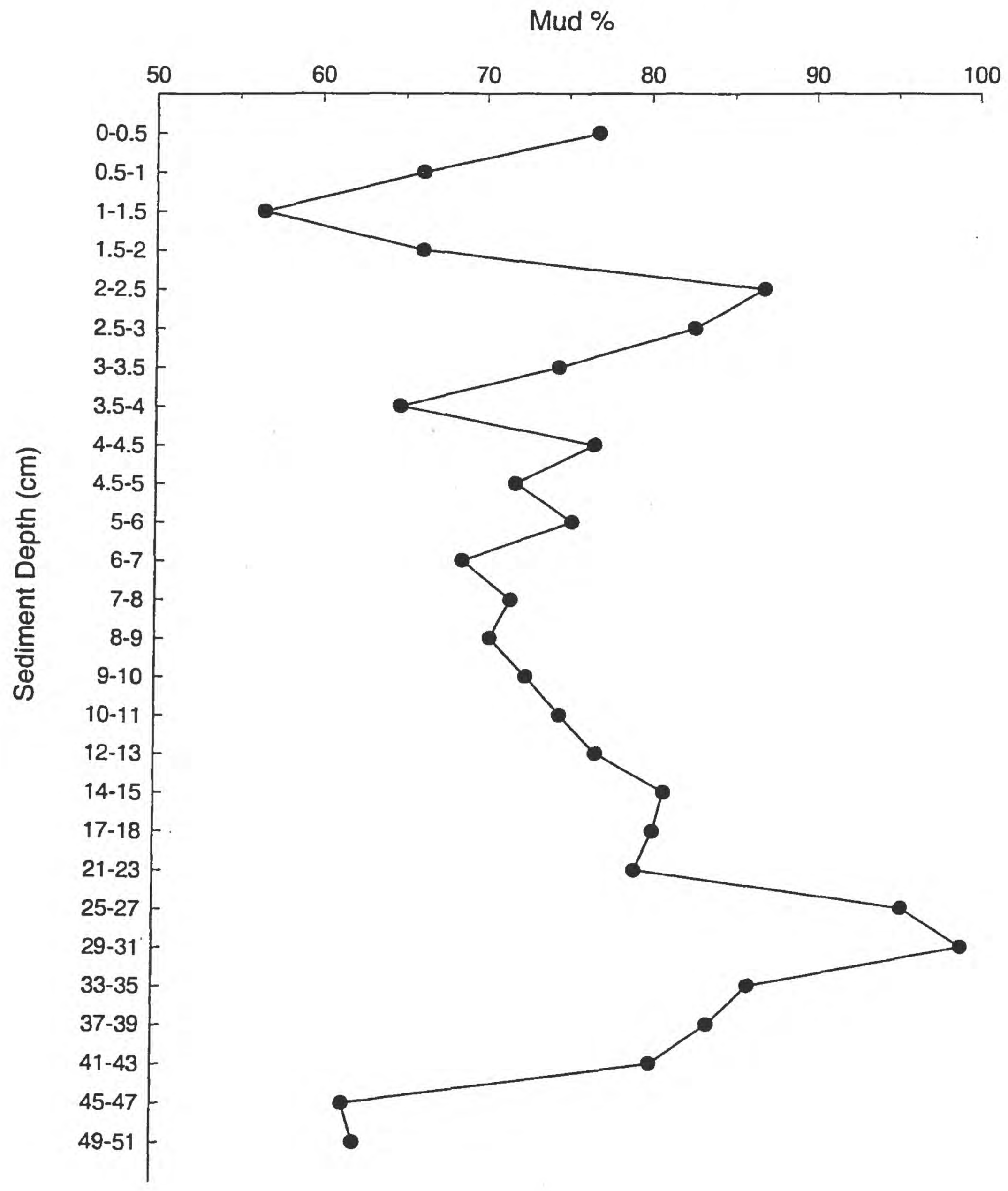



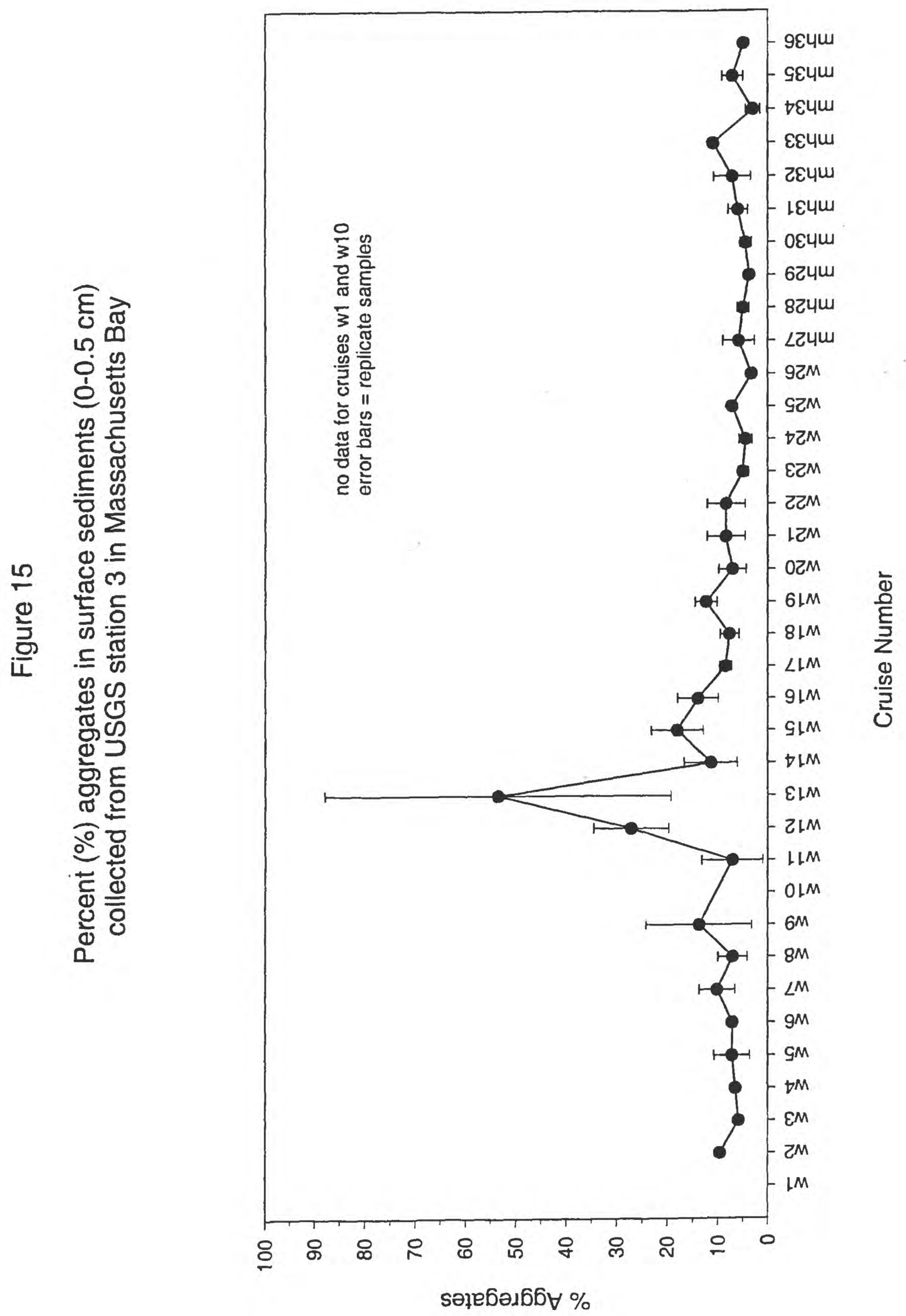
Figure 16

Percent (\%) aggregates with sediment depth in core 3-1 from cruise w15 at USGS station 3 in Massachusetts Bay

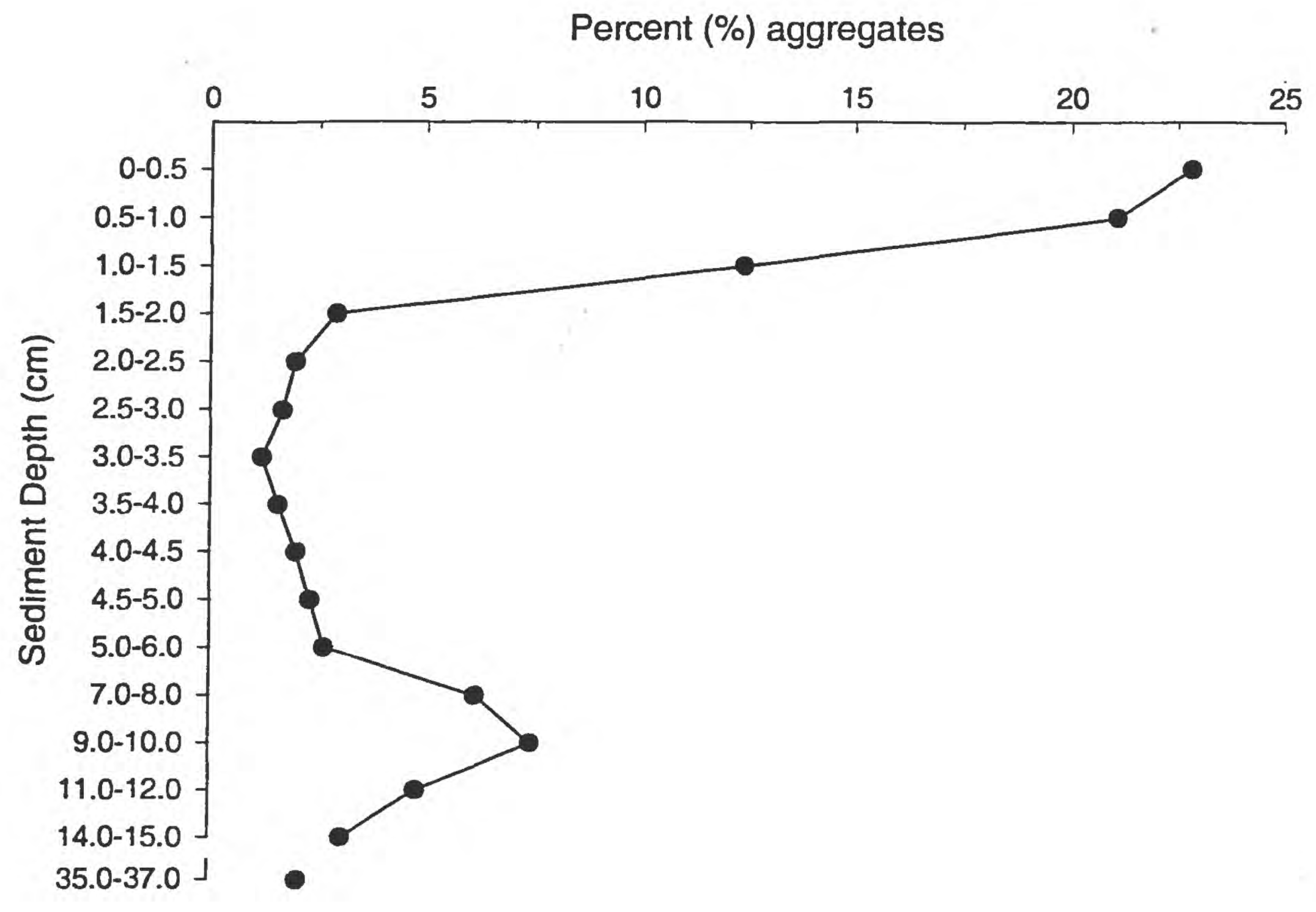


Figure 17

Percent (\%) aggregates with sediment depth in core 3-3 collected from cruise w15 at USGS station 3 in Massachusetts Bay

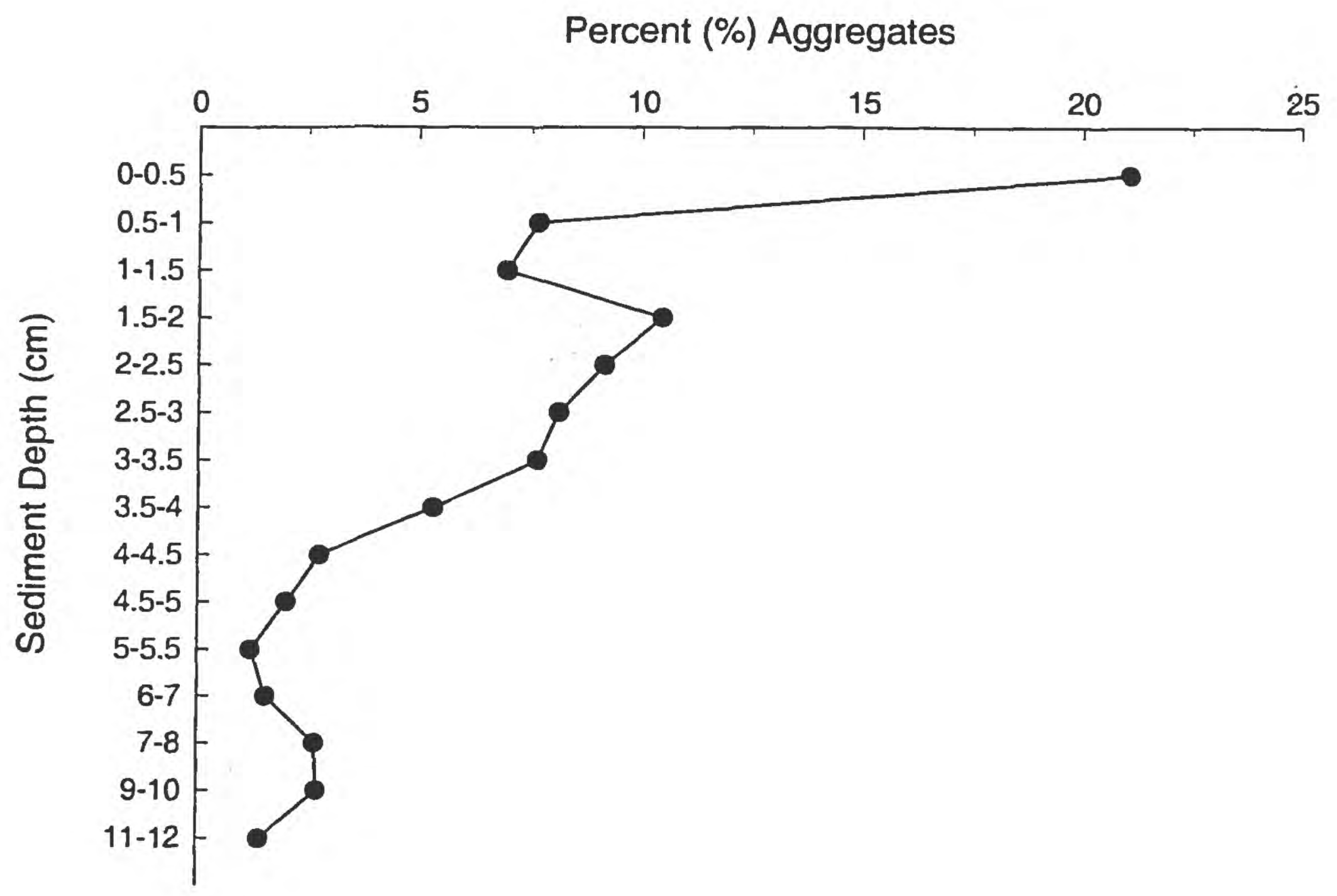


Figure 18

Percent (\%) aggregates with sediment depth in core 3-4 collected from cruise w24 at USGS station 3 in Massachusetts Bay

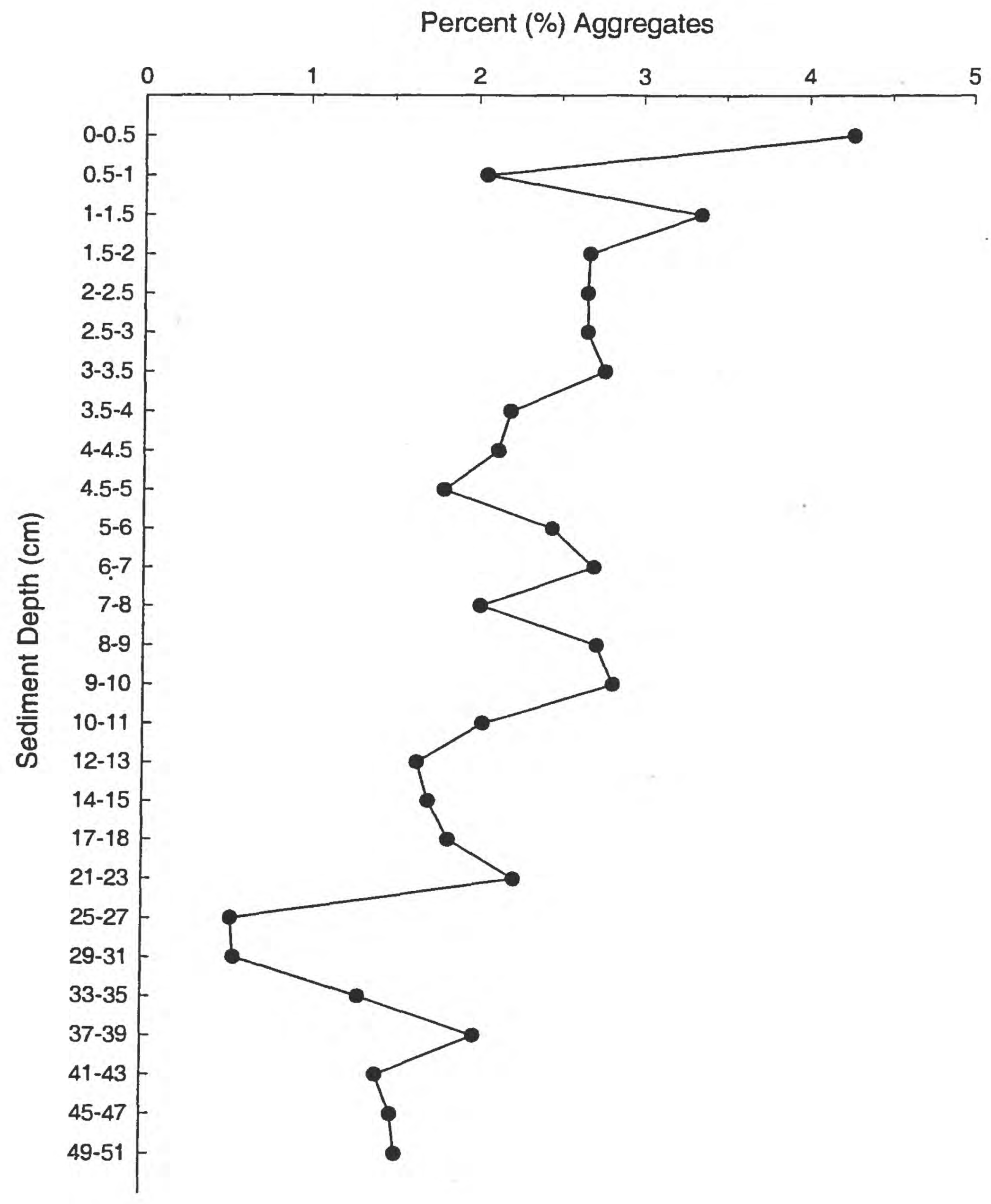




\begin{tabular}{|c|c|}
\hline 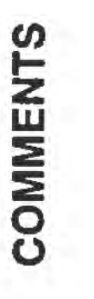 & 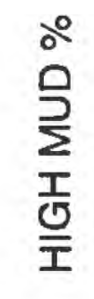 \\
\hline
\end{tabular}

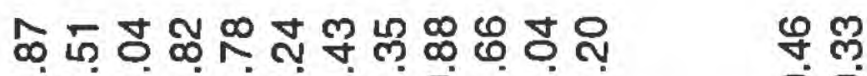

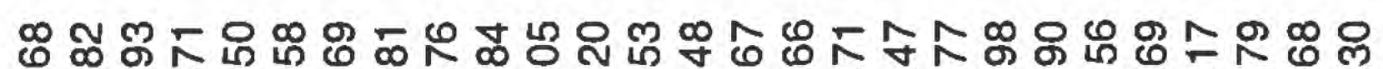

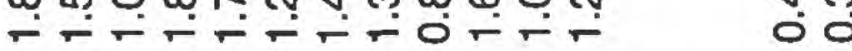

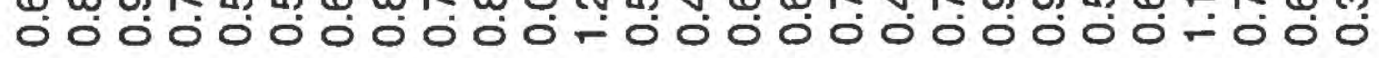

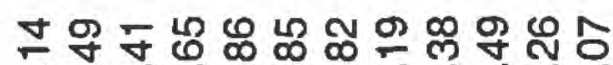

\&

$=\stackrel{n}{n}$

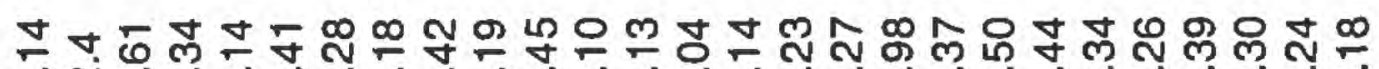

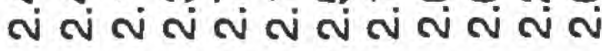

กิ

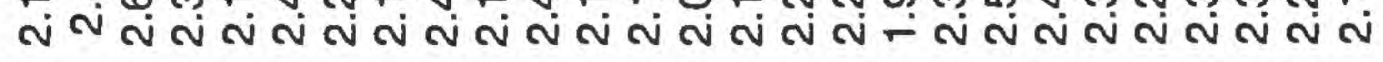

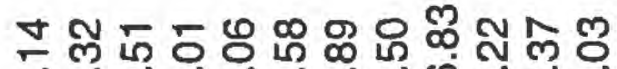

중

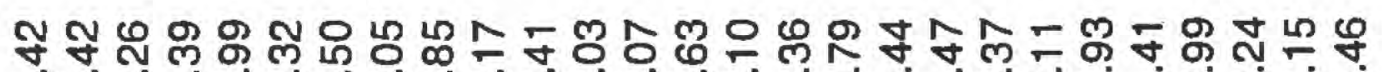

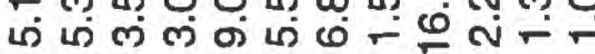

$-0$

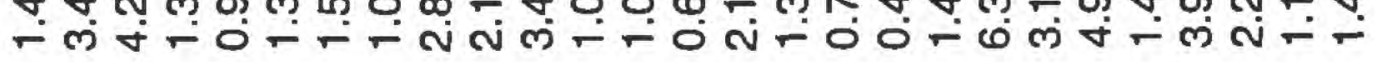

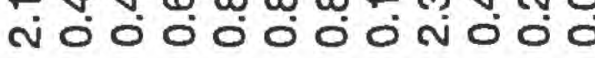

용

\%ั

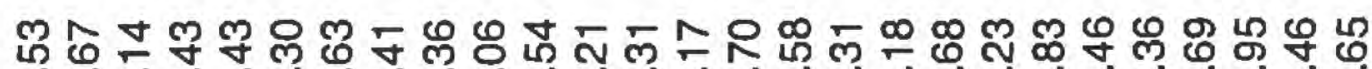

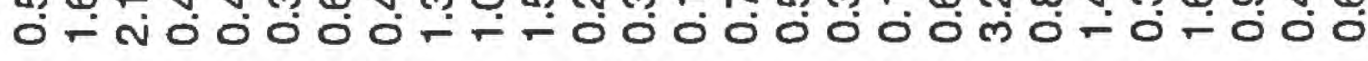

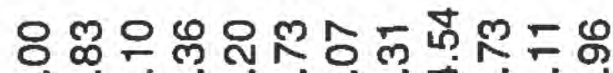

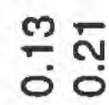

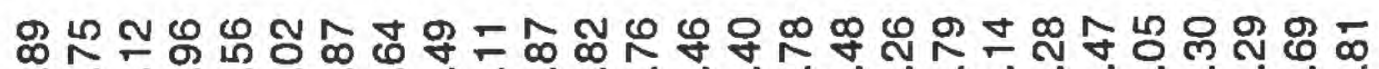

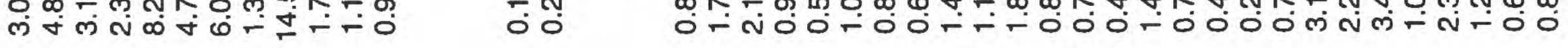

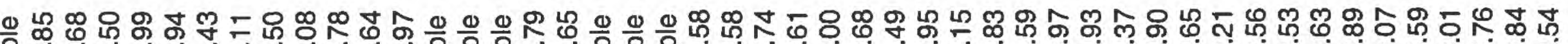

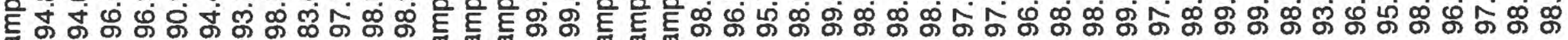
ஃ ㅀㅀ

풀을

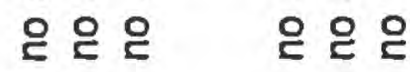

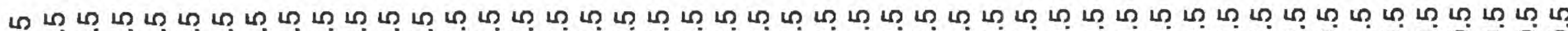

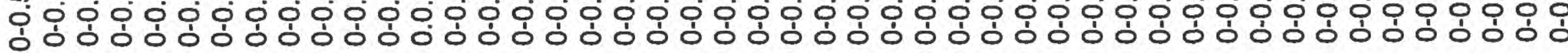

Uᄀレ UNM

근

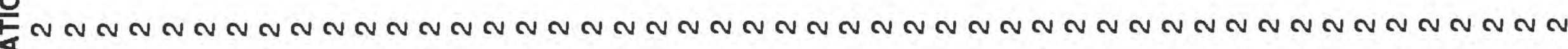
5

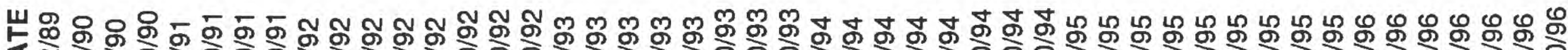

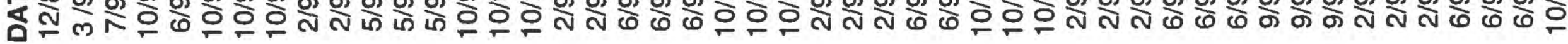

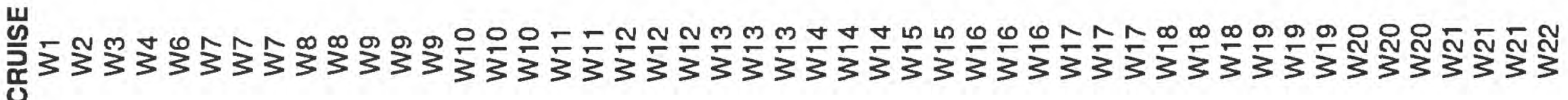




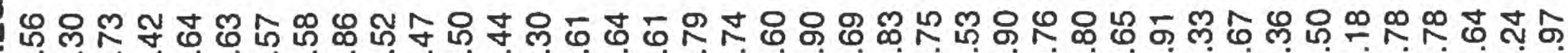

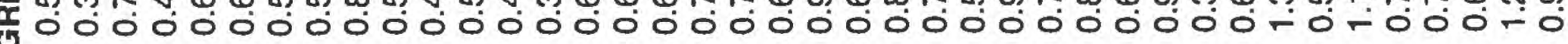
4

○’

퐁

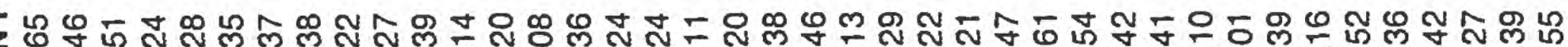
II N

일 。

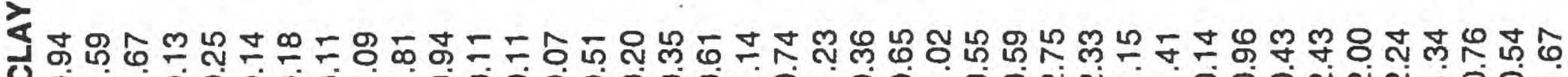
๙ீ

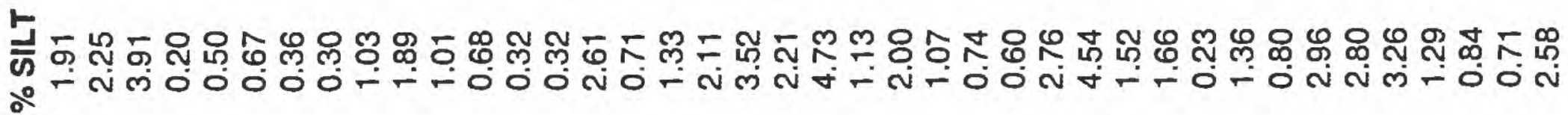

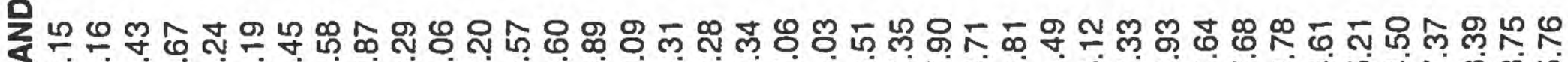

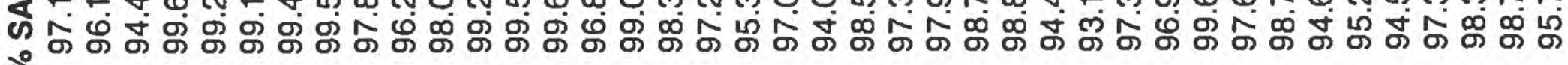
วீ

$\sum_{\substack{11 \\ 0}}^{\frac{1}{0}}$

$\widehat{\mathrm{E}}$

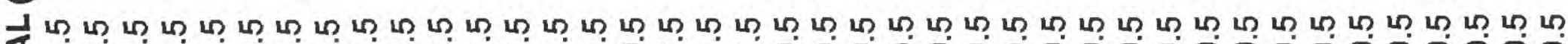
$\$ 0$ o 징 夏

崖

$\frac{u}{0}$

Z

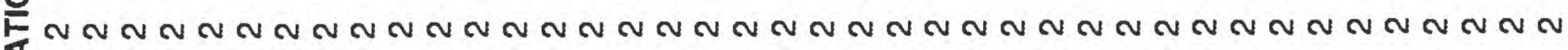
$\underset{5}{6}$

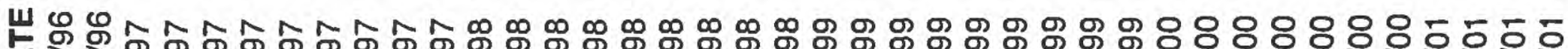
বั

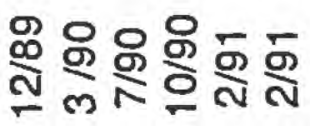

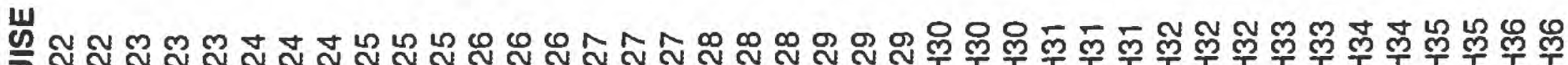

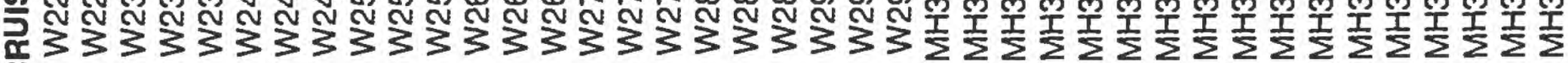

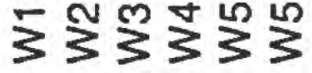

象舟守昌 ஸे

$\mathscr{0}$ जा

ำ ํํำ ณ 슘요

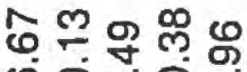
은웅

舫

๑ N $\mathscr{y}$ 空过

ما 잉잉ㅇํㅇㅇㅣ

$\infty \cup \varangle \infty 0$

ल ल ल ल 


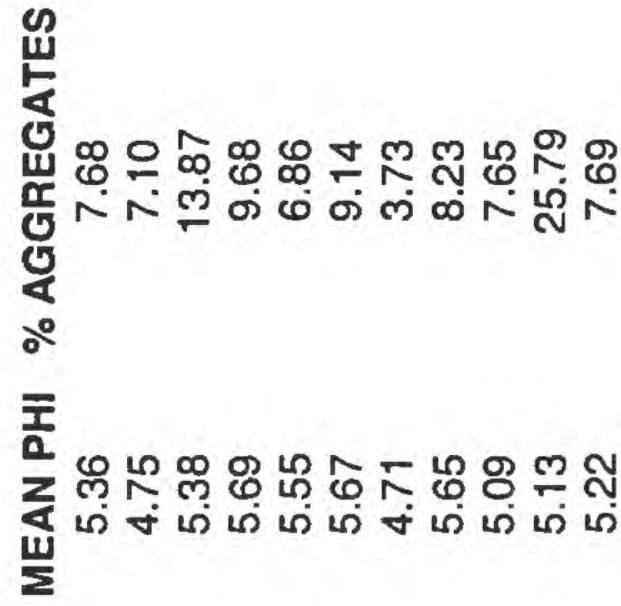

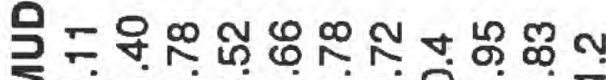
。ำ

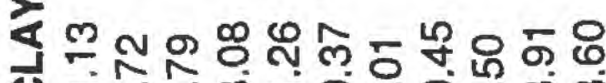
ơ

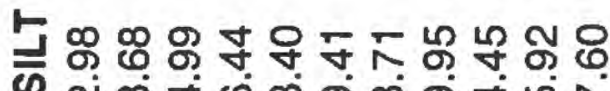

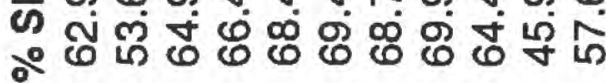

งโำ

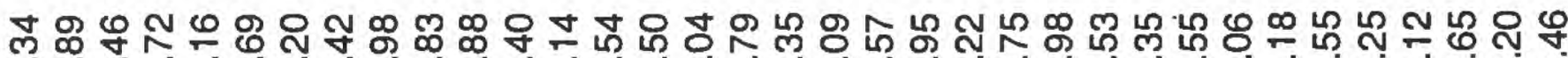
个ं

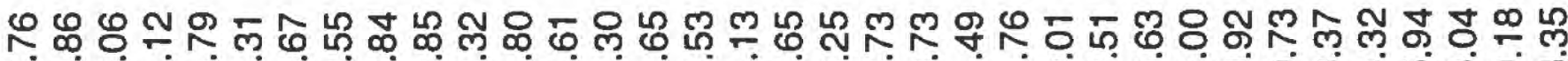

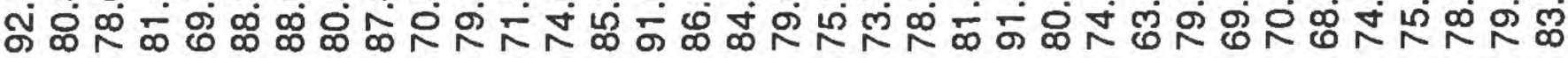

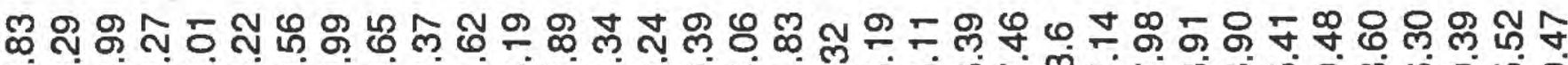

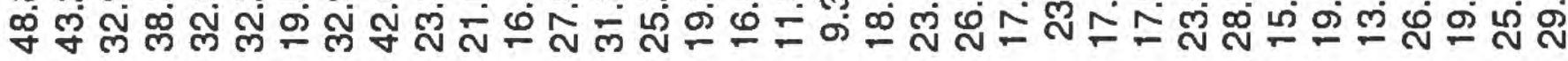

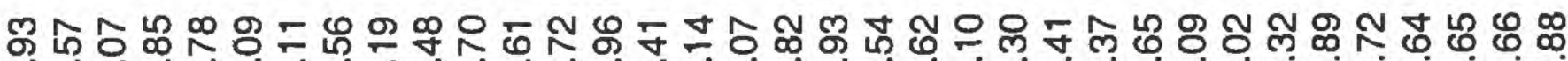

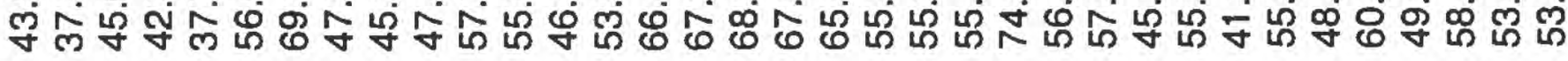

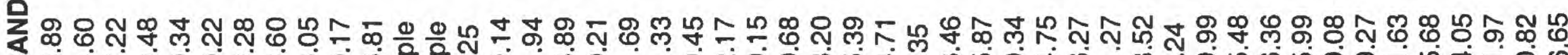

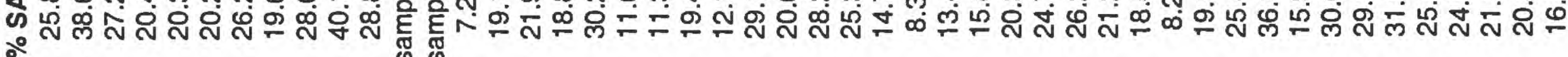

군은

峉

ஃீ

$\widehat{\mathrm{E}}$

صا భ

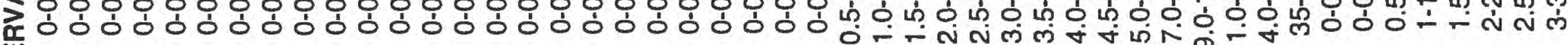
焉

\#

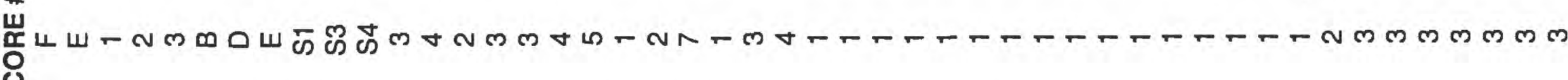
O

z

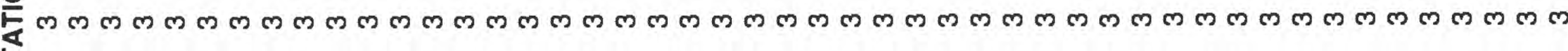
e

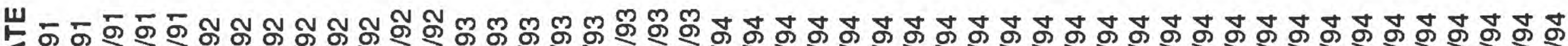

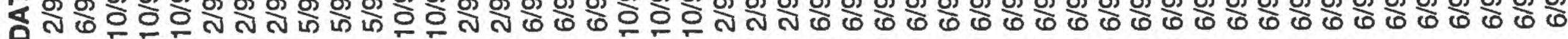

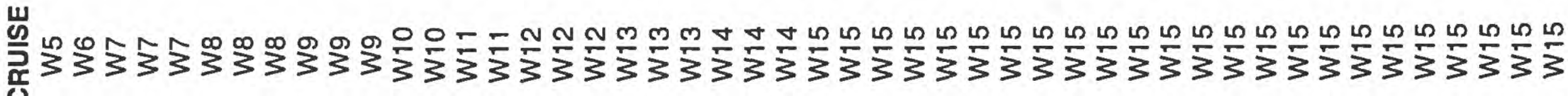




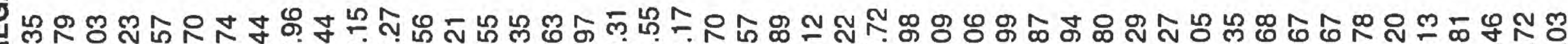
荷

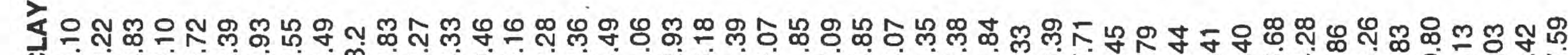

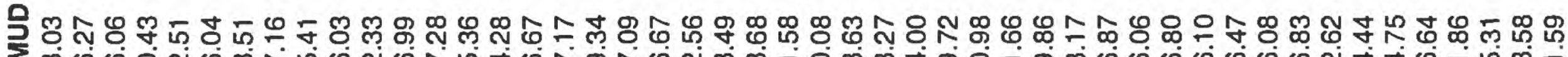
ஃ லீ

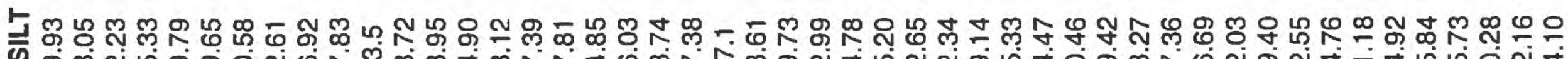
๑ீ

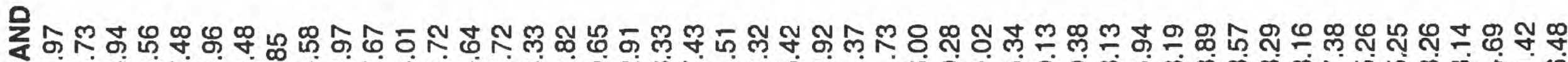
d゚ =

$\stackrel{\mathscr{Q}}{-}$

○

$\widehat{\text { E }}$

选 选 แ

$\underline{\underline{E}}$

\#

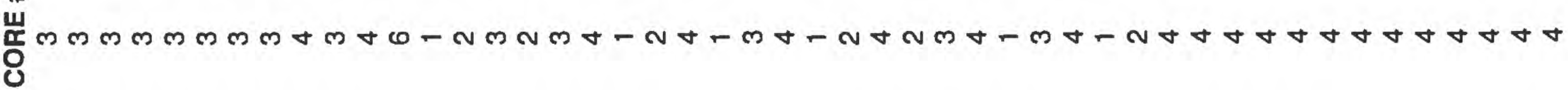
Z

एँ

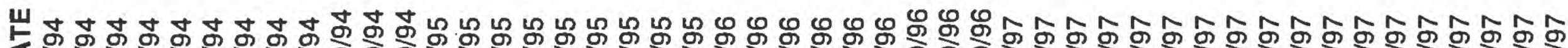
ठิ

岗以nแ 西 


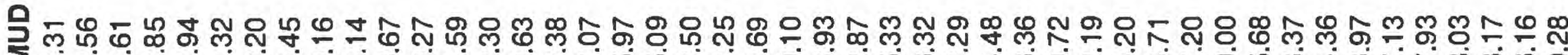

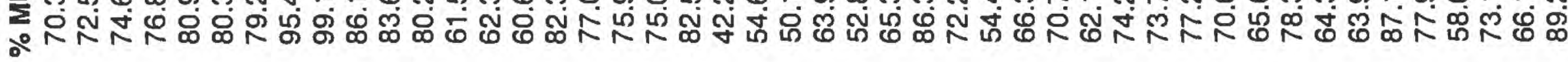

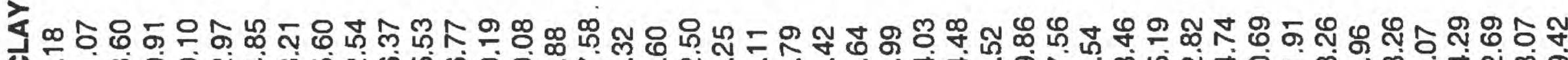

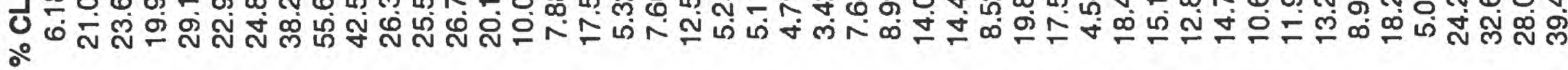

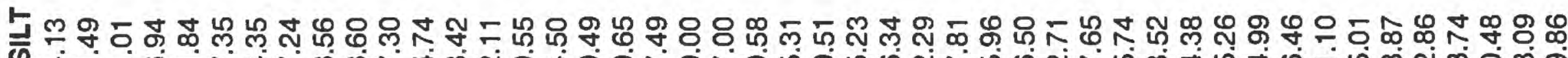

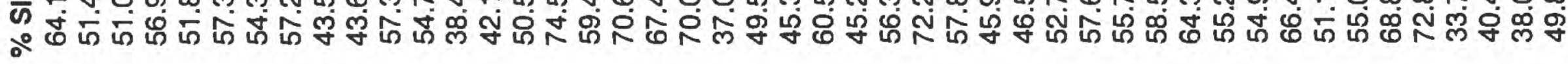

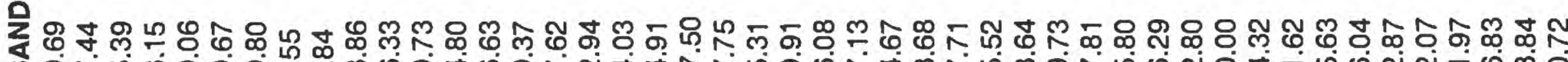

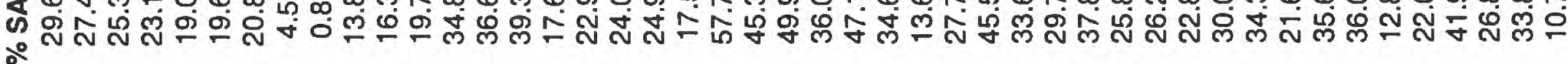<smiles>[10BH]</smiles><smiles></smiles>

$\stackrel{\varnothing}{-}$ $\therefore$

产

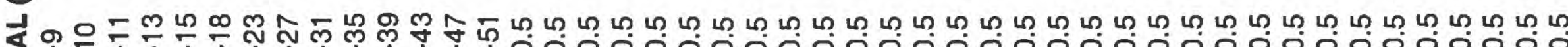

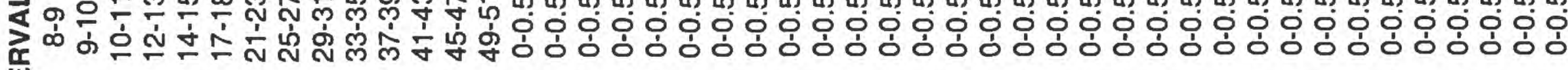
س $\underline{\underline{s}}$

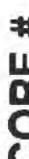

㟧

Z

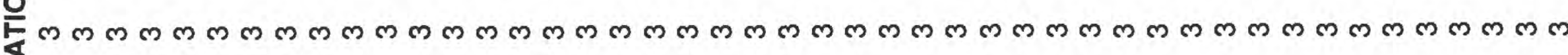
s

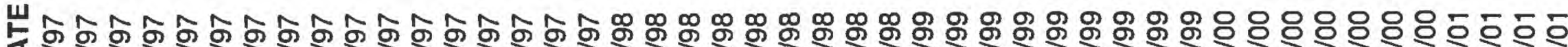

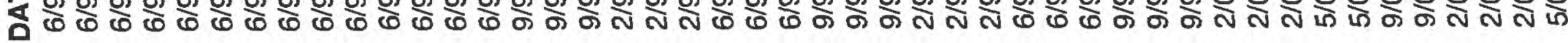

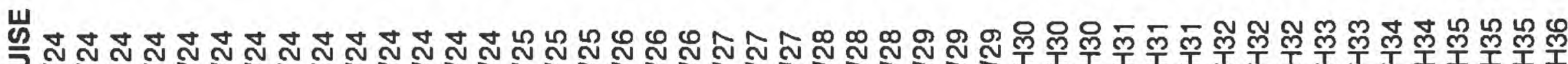

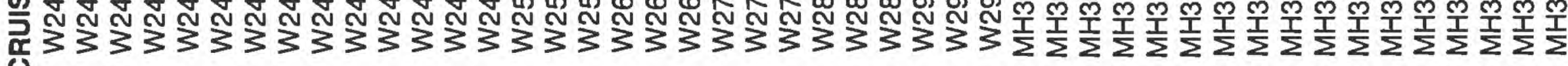




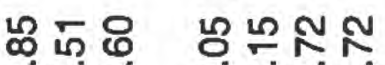

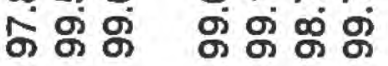

సิำ ్ำ

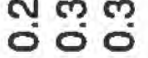

웅

$\frac{m}{0}=$

ळ

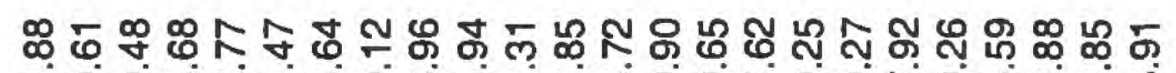

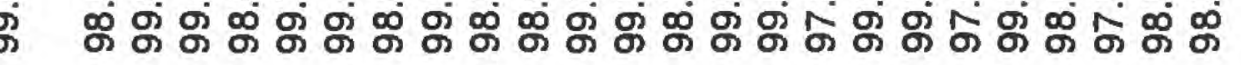

혼

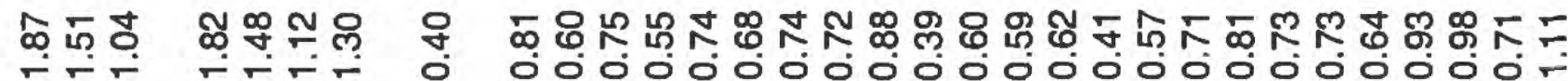
$\therefore$

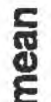

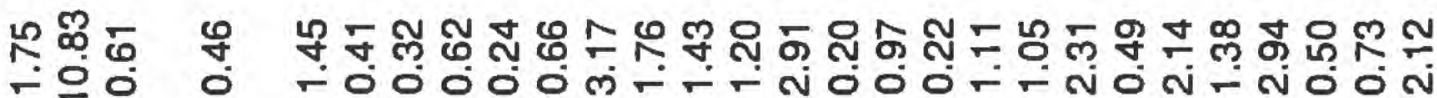

짙듀

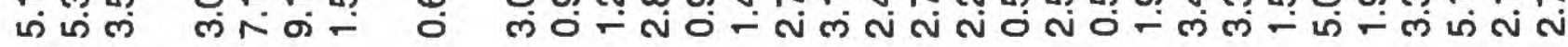

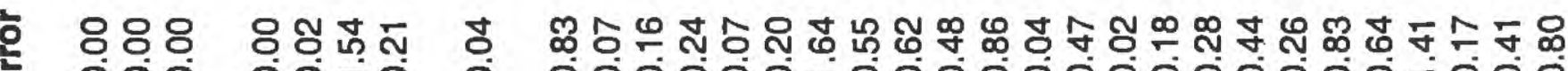

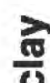

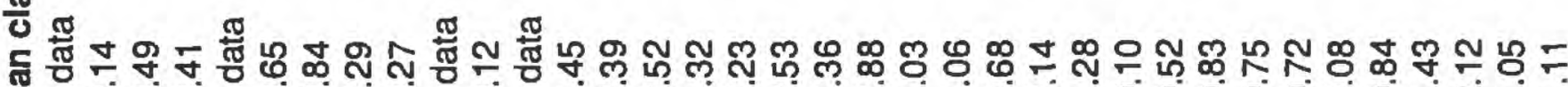
先 N ๙

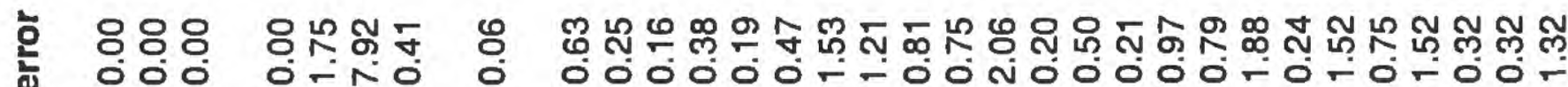

픈

爱 ह o ஃ

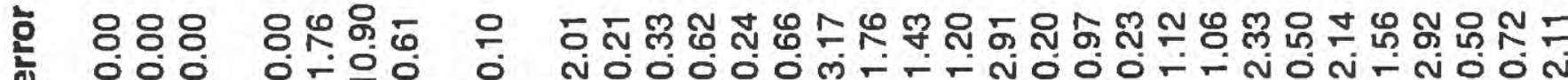

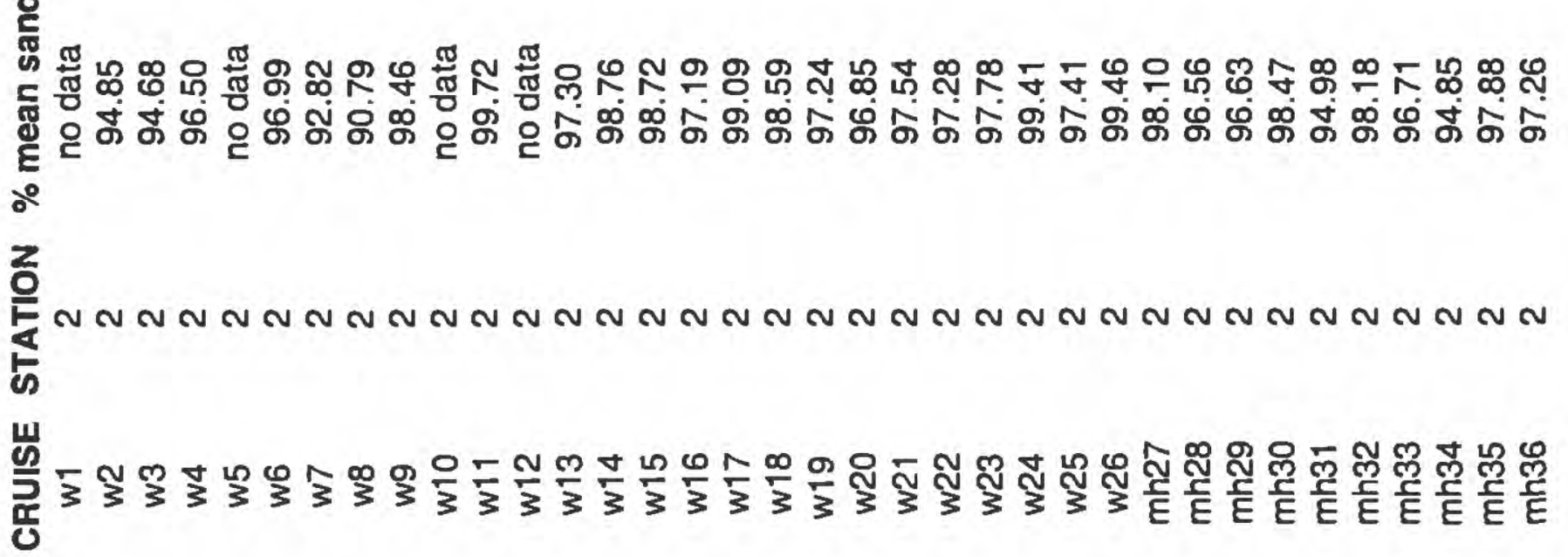

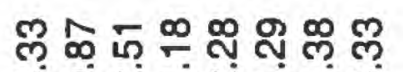

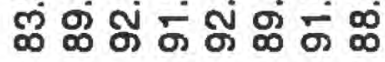

นㅇํㅇำ ஸिं

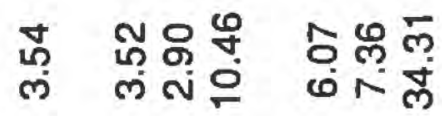

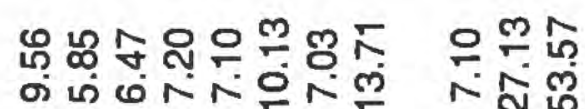

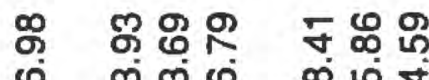

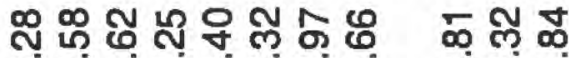

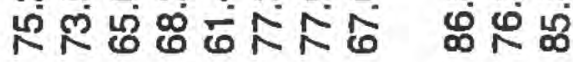

888

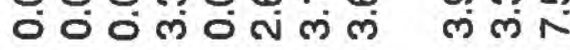

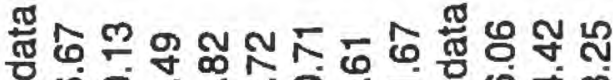

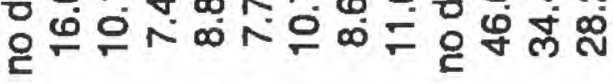

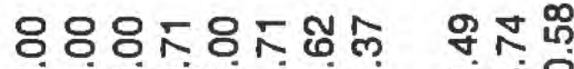

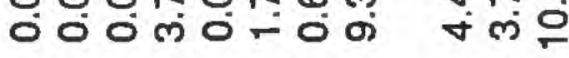

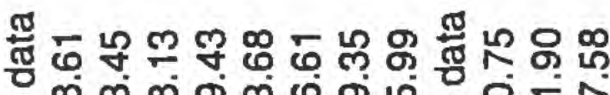

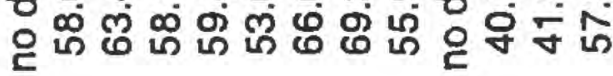

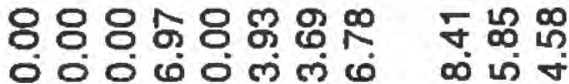

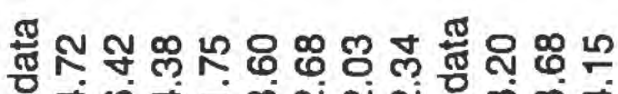

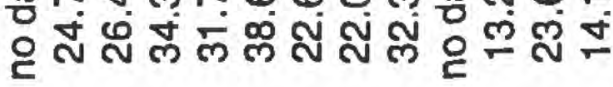

m

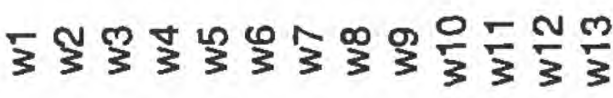




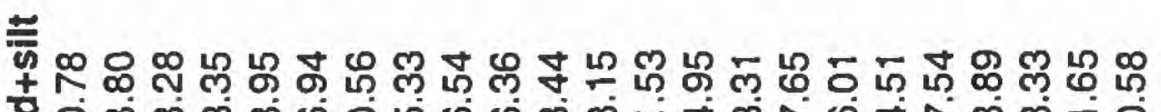

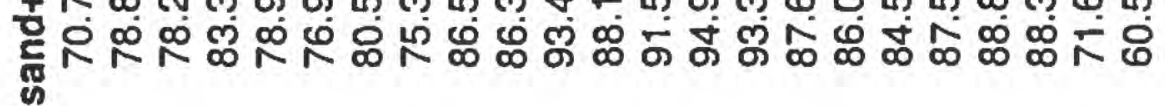

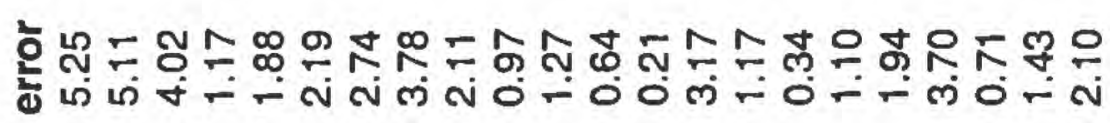

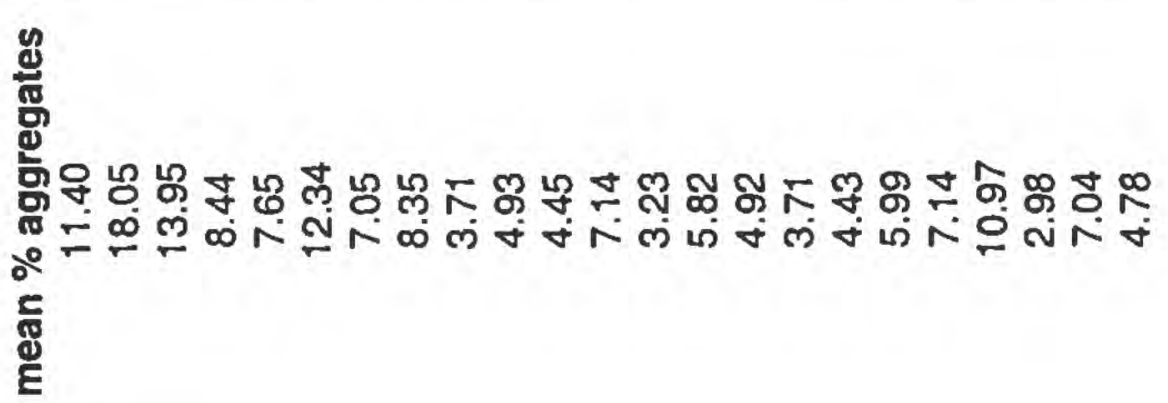

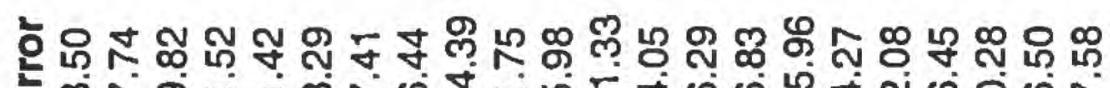

를

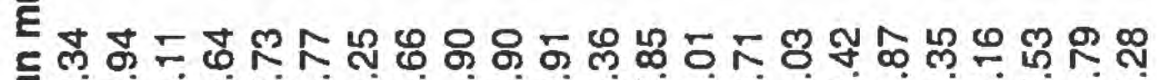

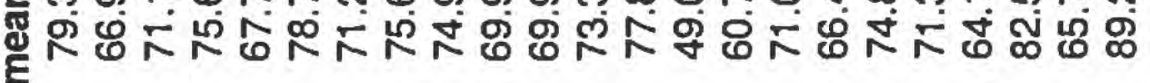
$\therefore$

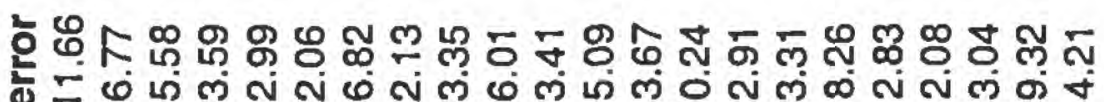

䆓

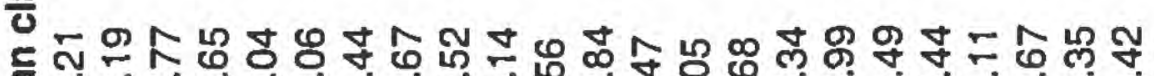

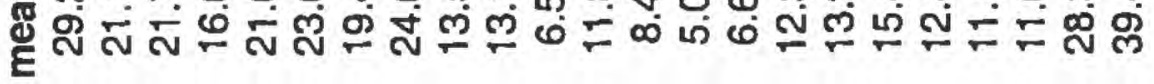
\&

흥

䓂

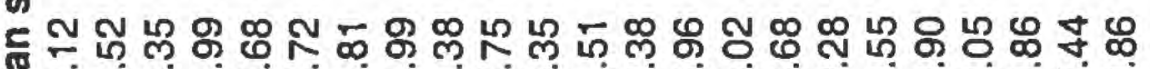

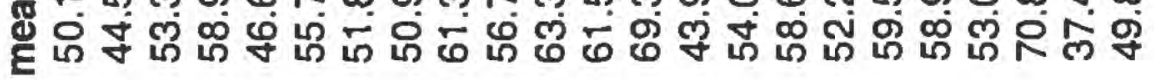
$\therefore$

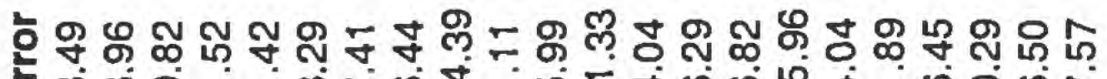

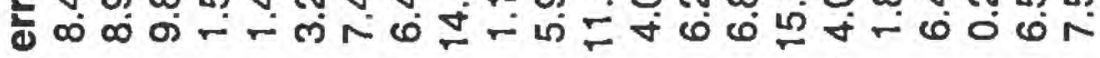

蛋

แ

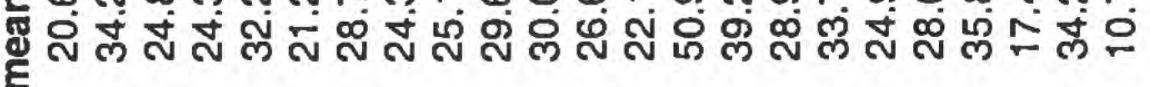
o̊

zo

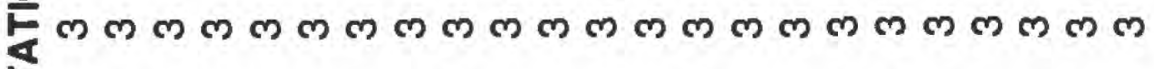
es

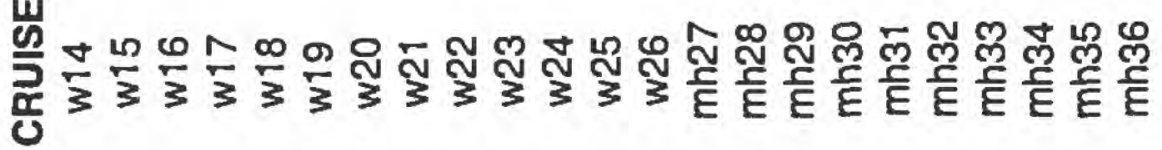

